Seleção de características apoiada por mineração visual de dados 


\title{
Seleção de características apoiada por mineração visual de dados
}

\author{
Glenda Michele Botelho
}

Orientador: Prof. Dr. João do Espírito Santo Batista Neto

Dissertação apresentada ao Instituto de Ciências Matemáticas e de Computação - ICMC-USP, como parte dos requisitos para obtenção do título de Mestre em Ciências - Ciências de Computação e Matemática Computacional. VERSÃO REVISADA.

USP - São Carlos

Março/2011 
Ficha catalográfica elaborada pela Biblioteca Prof. Achille Bassi e Seção Técnica de Informática, ICMC/USP, com os dados fornecidos pelo(a) autor(a)

Botelho, Glenda Michele
Seleção de características apoiada por mineração
visual de dados / Glenda Michele Botelho; orientador
João do Espírito Santo Batista Neto -- São Carlos,
2011.
$84 \mathrm{p.}$
Dissertação (Mestrado - Programa de Pós-Graduação en
Ciências de Computação e Matemática Computacional) --
Instituto de Ciências Matemáticas e de Computação,
Universidade de São Paulo, 2011.
1. Seleção de características. 2. Projeção de dados
multidimensionais. 3. Saliência de redes neurais
artificiais. 4. Agrupamento. I. Batista Neto, João
do Espírito Santo, orient. II. Título.



Àqueles que amo demais... 


\section{Agradecimentos}

À Deus, por todas as bençãos a mim concedidas;

Ao meu orientador, Prof. Dr. João Batista Neto, pela atenção, paciência e competência em orientar e motivar;

À minha avó Helena, à minha mãe Elenita e à minha irmã Gleice, pelo amor, compreensão, apoio e, principalmente, por aceitarem minha ausência;

Ao meu bem, Bruno Eliam, pelo amor e atenção, por suportar meu stress e tornar meu último ano de mestrado mais feliz;

Às minhas companheiras de apartamento, Daniella, Fabyana e Sara, pelos bons momentos compartilhados;

À minha amiga Virgínia, pela presença sempre compreensiva e alegre;

Ao meu amigo Sérgio, por todo apoio e ajuda durante o mestrado;

Aos meus amigos do ICMC, pelos momentos de estudo e lazer;

À CAPES, pelo apoio financeiro;

Enfim, a todas as pessoas que, de uma forma ou de outra, vem contribuindo com meu crescimento profissional e pessoal. 
"Suba o primeiro degrau com fé.

Você não precisa ver a escadaria inteira.

Apenas dê o primeiro passo."

Martin Luther King 


\section{Resumo}

Devido ao crescimento do volume de imagens e, consequentemente, da grande quantidade e complexidade das características que as representam, surge a necessidade de selecionar características mais relevantes que minimizam os problemas causados pela alta dimensionalidade e correlação e que melhoram a eficiência e a eficácia das atividades que utilizarão o conjunto de dados. Existem diversos métodos tradicionais de seleção que se baseiam em análises estatísticas dos dados ou em redes neurais artificiais. Este trabalho propõe a inclusão de técnicas de mineração visual de dados, particularmente, projeção de dados multidimensionais, para apoiar o processo de seleção. Projeção de dados busca mapear dados de um espaço $m$-dimensional em um espaço $p$-dimensional, $p<m$ e geralmente igual a 2 ou 3 , preservando ao máximo as relações de distância existentes entre os dados. Tradicionalmente, cada imagem é representada por um ponto e pontos projetados próximos uns aos outros indicam agrupamentos de imagens que compartilham as mesmas propriedades. No entanto, este trabalho propõe a projeção de características. Dessa forma, ao selecionarmos apenas algumas amostras de cada agrupamento da projeção, teremos um subconjunto de características, configurando um processo de seleção. A qualidade dos subconjuntos de características selecionados é avaliada comparando-se as projeções obtidas para estes subconjuntos com a projeção obtida com conjunto original de dados. Isto é feito quantitativamente, por meio da medida de silhueta, e qualitativamente, pela observação visual da projeção. Além da seleção apoiada por projeção, este trabalho propõe um aprimoramento no seletor de características baseado no cálculo de saliências de uma rede neural Multilayer Perceptron. Esta alteração, que visa selecionar características mais discriminantes e reduzir a quantidade de cálculos para se obter as saliências, utiliza informações provenientes dos agrupamentos de características, de forma a alterar a topologia da rede neural em que se baseia o seletor. Os resultados mostraram que a seleção de características baseada em projeção obtém subconjuntos capazes de gerar novas projeções com qualidade visual satisfatória. Em relação ao seletor por saliência proposto, este também gera subconjuntos responsáveis por altas taxas de classificação de imagens e por novas projeções com bons valores de silhueta.

Palavras-chave: Seleção de características, projeção de dados multidimensionais, seleção por saliência, agrupamento, silhueta. 


\section{Abstract}

Due to the ever growing amount of digital images and, consequently, the quantity and complexity of your features, there has been a need to select the most relevant features so that not only problems caused by high dimensional data sets, correlated features can be minimized, and also the efficiency of the tasks that may employ such features can be enhanced. Many feature selection methods are based on statistical analysis or neural network approaches. This work proposes the addition of visual data mining techniques, particularly multidimensional data projection approaches, to aid the feature selection process. Multidimensional data projection seeks to map a $m$-dimensional data space onto a $p$-dimensional space, so that $p<m$, usually 2 or 3, while preserving distance relationship among data instances. Traditionally, each image is represented by a point, and points projected close to each other indicate clusters of images which share a common properties. However, this work proposes the projection of features. Hence, if we select only a few samples of each cluster of features from the projection, we will end up with a subset of features, revealing a feature selection process. The quality of the feature subset may be assessed by comparing such projections with those obtained with the original data set. This can be achieved either quantitatively, by means of silhouette measures, or qualitatively, by means of visual inspection of the projection. As well as the projection based feature selection, this work proposes an enhancement in the Multilayer Perceptron salience based feature selector. This enhancement, whose aim is to perfect the selection of more discriminant features at the expenses of less computing power, employs information from feature clusters, so as to change the topology of the neural network on which the selector is based. Results have shown that projection-based feature selection produces subsets capable of generating new data projections of satisfactory visual quality. As for the proposed salience-based selector, new subsets with high image classification rates and good silhouette measures have been reported.

Keywords: Feature selection, multidimensional data projection, salience selection, clustering, silhouette. 


\section{Sumário}

Lista de Figuras $\quad$ vii

Lista de Tabelas $\quad$ xi

Lista de Trabalhos Publicados $\quad$ xiii

1 Introdução 1

1.1 Contextualização e Motivação . . . . . . . . . . . . . . . . . . . . . . . 1

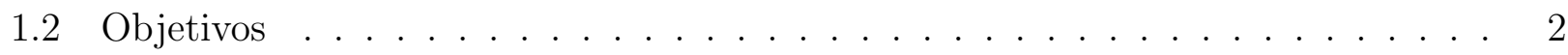

1.3 Organização do Trabalho . . . . . . . . . . . . . . . . . . . . . . . 4

2 Seleção de Características $\quad 6$

2.1 Considerações Iniciais . . . . . . . . . . . . . . . . . . . . . . . . 6

2.2 Maldição da Dimensionalidade . . . . . . . . . . . . . . . . . . 7

2.3 Seleção de Características . . . . . . . . . . . . . . . . . . . . 8

2.3.1 Passos Principais do Processo de Seleção de Características . . . . . . . . 8

2.3.2 Métodos de Seleção de Características . . . . . . . . . . . . . . . . . . . 10

2.4 Avaliação dos Subconjuntos de Características Selecionados . . . . . . . . . . . . 18

2.5 Considerações Finais . . . . . . . . . . . . . . . . . . . . . . . 20

3 Conceitos de Projeções e Agrupamentos $\quad 22$

3.1 Considerações Iniciais . . . . . . . . . . . . . . . . . . . . . . . . . . . . . . . 22

3.2 Projeção de Dados Multidimensionais . . . . . . . . . . . . . . . . . . . . 22

3.2 .1 Técnicas de Projeção Utilizadas . . . . . . . . . . . . . . . . . . 23

3.2 .2 Medida de Silhueta . . . . . . . . . . . . . . . . . . . 26

3.2.3 Ferramentas PEx e PEx-Image . . . . . . . . . . . . . . 26 
3.3 Agrupamento . . . . . . . . . . . . . . . . . . . . . . . . 29

3.3.1 Algoritmo KGA-clustering . . . . . . . . . . . . . . . 30

3.3.2 Encontrando o Número Correto de Agrupamentos . . . . . . . . . . . . . 31

3.4 Considerações Finais . . . . . . . . . . . . . . . . . . . . . . . . . . . 32

4 Abordagem Proposta para a Seleção de Características $\quad 34$

4.1 Considerações Iniciais . . . . . . . . . . . . . . . . . . . . . . . . . 34

4.2 Abordagem Proposta . . . . . . . . . . . . . . . . . . 34

4.2.1 Seletor por Saliência Proposto . . . . . . . . . . . . . . . 36

4.2.2 Estratégias de Treino e Teste da Rede Neural . . . . . . . . . . . . . . 38

4.3 Conjuntos de Imagens e Extratores de Características Utilizados . . . . . . . . . 39

4.4 Considerações Finais . . . . . . . . . . . . . . . . . . . . . . . . 41

5 Resultados $\quad 42$

5.1 Considerações Iniciais . . . . . . . . . . . . . . . . . . . . . . . . . 42

5.2 Experimento 1. . . . . . . . . . . . . . . . . . . . 42

5.3 Experimento $2 \ldots \ldots \ldots \ldots \ldots$

5.4 Experimento $3 \ldots \ldots \ldots \ldots \ldots \ldots \ldots \ldots$

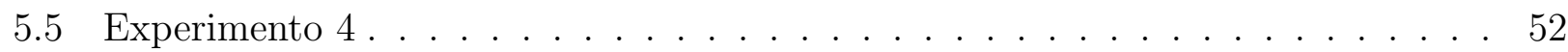

5.6 Considerações Finais . . . . . . . . . . . . . . . . . . . . . . . . 56

6 Conclusões $\quad 57$

6.1 Limitações . . . . . . . . . . . . . . . . . . . . . . . . . 58

6.2 Contribuições . . . . . . . . . . . . . . . . . . . . . . . . . 59

6.3 Trabalhos Futuros . . . . . . . . . . . . . . . . . . . . . . . . 59

$\begin{array}{ll}\text { Bibliografia } & 61\end{array}$ 


\section{Lista de Figuras}

2.1 Taxonomia dos métodos de seleção de características apresentada por Jain e Zongker [Jain and Zongker 1997]. . . . . . . . . . . . . . . . . 10

2.2 Representação de cromossomo em seleção de características. . . . . . . . . . . . 14

2.3 Modelo de um neurônio artificial. . . . . . . . . . . . . . . . . . . 15

2.4 Topologia tradicional de um seletor de características por saliência baseado em rede neural MLP . . . . . . . . . . . . . . . . . . . . . . . 18

3.1 Exemplo de Projeção 2D do conjunto de dados IRIS. Cada cor indica uma classe diferente. . . . . . . . . . . . . . . . . . 24

3.2 Projeção 2D de um conjunto de imagens médicas usando a técnica $N J$ com modelos em árvore filogenética. . . . . . . . . . . . . . . . 28

3.3 Projeção 3D de um conjunto de 2800 artigos científicos: a) projeção 3D onde cada vértice representa um artigo e cada cor, uma categoria de artigos; b) conjunto de agrupamentos representados por feixos convexos. . . . . . . . . . . . . . 28

4.1 Diagrama referente à abordagem de seleção proposta neste trabalho. . . . . . . . 35

4.2 Nova configuração do seletor por saliência baseado em $M L P$ com informações provenientes de grupos de características. . . . . . . . . . . . . 37

4.3 Conjunto de Imagens Rotate: Uma amostra de cada classe, considerando o ângulo de $\operatorname{rotação~} 0^{\circ} \ldots \ldots \ldots$. . . . . . . . . . . . . . . 40

4.4 Mosaico de textura de madeira com quatro classes: $0^{\circ}$ (acima esq.), $30^{\circ}$ (acima dir.), $60^{\circ}$ (abaixo esq.) e 90 (abaixo dir.). . . . . . . . . . . . . . . . 40

4.5 Conjunto de Imagens Scene: exemplos de amostras das classes construções, costas oceânicas e florestas. . . . . . . . . . . . . . . . . . . . . . 40 
5.1 Projeção das 240 amostras. (a) Projeção do conjunto original de dados. (b) Projeção dos dados transpostos com os quatro agrupamentos computados por K-means (cada ponto indica uma característica) . . . . . . . . . . . . . . 43

5.2 Projeção das 240 imagens. (a) Subconjunto de características selecionado pela aplicação do K-means sobre os dados projetados. (b) Subconjunto de características selecionado pela aplicação do K-means diretamente no conjunto transposto.

5.3 Projeção das 200 amostras. (a) Projeção do conjunto original de dados. (b) Projeção dos dados transpostos (cada ponto representa uma característica). . . . 46

5.4 Projeções das 200 imagens. (a) Subconjunto de características selecionado visualmente. (b) Subconjunto de características selecionado pela aplicação do K-means diretamente no conjunto transposto. . . . . . . . . . . . . . . 46

5.5 Técnica de Projeção Sammon's Mapping. (a) Projeção do conjunto original de dados. (b) Subconjunto de características selecionado pelo seletor proposto por Santos. (c) Subconjunto de características selecionado pelo seletor proposto neste trabalho.

5.6 Técnica de Projeção Classical Scaling. (a) Projeção do conjunto original de dados. (b) Subconjunto de características selecionado pelo seletor proposto por Santos. (c) Subconjunto de características selecionado pelo seletor proposto neste trabalho.

5.7 Técnica de Projeção Least Square Projection. (a) Projeção do conjunto original de dados. (b) Subconjunto de características selecionado pelo seletor proposto por Santos. (c) Subconjunto de características selecionado pelo seletor proposto neste trabalho.

5.8 Projeção das 200 imagens para todas as características utilizando a técnica Least Square Projection. . . . . . . . . . . . . . . . . . . . 52

5.9 Técnica de Projeção Least Square Projection. (a) Projeção dos dados transpostos. Cada ponto representa uma característica. (b) Projeção das imagens para o subconjunto de 30 características. . . . . . . . . . . . . . . . . 53

5.10 Projeção das 200 imagens para todas as características utilizando a técnica Classical Scaling. . . . . . . . . . . . . . . . . . . . . . . . 53

5.11 Técnica de Projeção Classical Scaling. (a) Projeção dos dados transpostos. Cada ponto representa uma característica. (b) Projeção das imagens para o subconjunto de 30 características. . . . . . . . . . . . . . . . . . . . . . . . 53 
5.12 Projeção das 200 imagens para todas as características utilizando a técnica Sammon's Mapping. . . . . . . . . . . . . . . . . . . . . . . . . . . 54

5.13 Técnica de Projeção Sammon's Mapping. (a) Projeção dos dados transpostos. Cada ponto representa uma característica. (b) Projeção das imagens para o subconjunto de 30 características. . . . . . . . . . . . . . . . . . . 54 


\section{Lista de Tabelas}

5.1 Medidas de silhueta obtidas das projeções para o conjunto de 240 imagens do banco Rotate. . . . . . . . . . . . . . . . . . . . . . . . . . . . 44

5.2 Medidas de silhueta obtidas das projeções para o conjunto de 748 imagens do banco Rotate . . . . . . . . . . . . . . . . . . . . . 45

5.3 Medidas de silhueta obtidas das projeções para o conjunto de 200 imagens do banco Scene. . . . . . . . . . . . . . . . . . . . . 46

5.4 Média da taxa de erro de classificação considerando os subconjuntos selecionados pelos seletores por saliência e o conjunto completo de características. . . . . . . . 47

5.5 Média das silhuetas obtidas para o conjunto de 784 imagens do banco Rotate, considerando diferentes técnicas de projeção. . . . . . . . . . . . . . . . . . . . 47

5.6 Média da taxa de erro de classificação considerando os subconjuntos selecionados pelos seletores por saliência, tratando a questão do número correto de agrupamentos. . . . . . . . . . . . . . . . . 5 . 50

5.7 Média das silhuetas obtidas para o conjunto de 200 imagens do banco Scene utilizando a técnica Sammon's Mapping. . . . . . . . . . . . . . . . . . 51

5.8 Média das silhuetas obtidas para o conjunto de 200 imagens do banco Scene utilizando a técnica Classical Scaling. . . . . . . . . . . . . . . . . . . 51

5.9 Média das silhuetas obtidas para o conjunto de 200 imagens do banco Scene utilizando a técnica Least Square Projection. . . . . . . . . . . . . . . . . . . . . 52

5.10 Medidas de silhueta obtidas das projeções para o conjunto de 200 imagens de cenas naturais, considerando diferentes técnicas. . . . . . . . . . . . . . 55

5.11 Medidas de silhueta para o conjunto de 200 imagens do banco Scene, considerando os subconjuntos selecionados visualmente. . . . . . . . . . . . . . . . . 55 
5.12 Medidas de silhueta para o conjunto de 200 imagens do banco Scene, considerando os subconjuntos selecionados aleatoriamente. . . . . . . . . . . . . 56 


\section{Trabalhos Publicados}

1. BOtelho, G. M.; BATISTA NETO, J. E. S. "Seleção de Características apoiada por Mineração Visual de Dados". In: Workshop de Visão Computacional, Presidente Prudente, 2010.

2. BOTELHO, G. M.; BATISTA NETO, J. E. S. "Seleção de Características apoiada por Mineração Visual de Dados", versão ampliada. In: Revista Learning and NonLinear Models, Sociedade Brasileira de Redes Neurais, 2011 (aceito). 
Capítulo 1

\section{Introdução}

\subsection{Contextualização e Motivação}

A popularização do uso de tecnologias geradoras de dados digitais, incluindo equipamentos que produzem imagens, quer seja para finalidades médico-terapêuticas, agricultura ou de entretenimento, permitiu o surgimento de grandes bancos de imagens digitais, ao mesmo tempo em que impôs grandes desafios aos desenvolvedores de sistemas que lidam com estes bancos de imagens.

Um destes desafios é a correta recuperação de imagens com base no conteúdo. Geralmente, um sistema de recuperação de imagens por conteúdo tem como entrada não a imagem em si, mas um conjunto de atributos numéricos, organizados no que comumente chamamos de vetor de características. Portanto, cada instância do conjunto de dados (imagem) é representada por um vetor de características, com uma ou mais dimensões. Características são extraídas de imagens por meio de extratores, que são algoritmos de processamento de imagens que procuram identificar atributos visuais (normalmente cor, forma ou textura) e traduzi-los em atributos numéricos.

Sabe-se ainda que um sistema de recuperação por conteúdo que exiba taxas de acerto razoáveis deve, via de regra, contemplar não apenas um único tipo de atributo visual, mas ao contrário, deve combinar uma série de atributos, o que pode gerar vetores de características de alta dimensionalidade, ou seja, com um número muito elevado de características.

No contexto de reconhecimento de padrões, vetores de características de alta dimensionalidade podem suscitar uma série de problemas, a saber: a) ao lançar mão de vários extratores, é possível que muitas das características produzidas sejam correlacionadas e/ou não tenham poder discriminatório esperado; b) a relação desproporcional entre a quantidade de características e o número de instâncias pode levar ao problema conhecido como maldição da dimensionalidade 
[Bellman 1957].

Em ambas as situações, o resultado é, invariavelmente, a degradação do desempenho das técnicas desenvolvidas para o armazenamento, manipulação e análise dos dados, como também um aumento considerável do custo computacional. Diante disto, a tarefa de redução da dimensionalidade do vetor de características é uma atividade bastante desejável.

A redução da dimensionalidade tem por objetivo eliminar do conjunto de dados, características que sejam correlacionadas, irrelevantes ou distorcidas. Essa redução pode ser feita por meio de extração ou seleção. No primeiro, o espaço original de características é transformado, gerando "novas" características, algumas das quais possuindo maior poder discriminatório que as suas versões originais. Dentre as técnicas de extração destacam-se Principal Component Analysis (PCA) [Jolliffe 1986] e Linear Discriminant Analysis (LDA) [Fisher 1938].

Os métodos de seleção, em contrapartida, procuram encontrar no espaço original o subconjunto de características com maior poder discriminatório, descartando aquelas que exibem pouca ou nenhuma relevância ou que sejam altamente correlacionadas a outras características. Na literatura, existem diferentes métodos de seleção de características [Jain and Zongker 1997; Kudo and Sklansky 2000; Liu and Yu 2005] que seguem o enfoque de reconhecimento de padrões e, portanto, se baseiam em alguma análise estatística dos dados ou, em outros casos, adotam uma abordagem de redes neurais. Ressalta-se que este trabalho tem como tema principal a seleção de características.

\subsection{Objetivos}

Neste trabalho propomos uma nova abordagem para a seleção de características que combina técnicas tradicionais de seleção com o auxílio da mineração visual de dados. A mineração visual de dados corresponde à fusão das áreas de mineração de dados (que busca extrair padrões de conjuntos de dados) e visualização de informações (que apóia o processo de mineração por meio de métodos visuais de apresentação e interação com dados abstratos) [Wong 1999]. Dentre as técnicas de mineração visual de dados estão as projeções de dados multidimensionais [Tejada et al. 2003].

A projeção consiste em mapear dados de um espaço $m$-dimensional em um espaço $p$ dimensional, com $p<m$, geralmente igual a 2 ou 3, buscando preservar ao máximo as relações de distância existentes entre os dados. Tradicionalmente, os pontos projetados correspondem às instâncias de dados, por exemplo, imagens. Pontos projetados próximos uns aos outros indicam agrupamentos de instâncias que compartilham as mesmas propriedades. Portanto, agrupamentos visualmente separáveis na projeção, indicam grupos de imagens semelhantes. 
$\mathrm{Na}$ abordagem proposta, ao invés de projetarmos as imagens como instância de dados, projetam-se as características. Acredita-se que a combinação de projeção de dados multidimensionais com o processo de seleção de características seja vantajosa, pois a avaliação da seleção, anteriormente baseada apenas em uma função estatística, conta agora com o ponto de vista de um observador (usuário) que avalia a qualidade do agrupamento fornecido pela projeção para um dado subconjunto de características. Além disso, pode-se explorar a viabilidade de realizar seleção de características de forma automática, combinando projeções com processos de agrupamento.

Para permitir a projeção de características, o conjunto original, representado por uma matriz $M_{n, m}$ composta por $n$ instâncias com $m$ características cada, deve ser transposto. A transposição resultará em um conjunto representado por uma matriz $M_{m, n}$ composta por $m$ instâncias (características) e $n$ dimensões (imagens). Tal matriz servirá como entrada para as técnicas de projeção, permitindo com que as características sejam projetadas e não mais as imagens. A projeção resultante consistirá, portanto, de $m$ amostras, cada qual representando uma característica. À exemplo da projeção tradicional, agrupamentos poderão ser gerados, só que neste caso em particular, serão agrupadas características. Se agrupamentos indicam instâncias com propriedades comuns, então podemos assumir que características pertencentes ao mesmo grupo possuem poder discriminatório semelhante. Ao selecionarmos apenas algumas amostras de cada agrupamento da projeção, teremos um subconjunto de características, configurando um processo de seleção. Ressalta-se que neste trabalho, o termo projeção de imagens será utilizado para designar $n$ pontos projetados, onde cada ponto representa uma imagem e, o termo projeção de características designa $m$ pontos projetados, onde cada ponto representa uma característica.

A qualidade dos subconjuntos de características selecionados pelo método proposto é avaliada comparando-se as projeções de imagens obtidas para estes conjuntos com a projeção obtida com conjunto original de dados. Para tanto, será utilizada a medida de silhueta [Kaufman and Rousseeuw 1990], que quantifica a qualidade da projeção de imagem, medindo o grau de coesão das amostras pertencentes à mesma classe e o grau de separação entre classes. Também é utilizado um classificador baseado em rede neural Multilayer Perceptron (MLP) para avaliar os subconjuntos por meio da taxa de erro de classificação das imagens, considerando os subconjuntos selecionados e o conjunto original.

Além da seleção de características baseada em projeção, o projeto propõe um aprimoramento no seletor de características baseado no cálculo de saliências de uma rede neural MLP, originalmente desenvolvido por Santos [Santos and Batista Neto 2007]. Esta alteração, que visa selecionar características mais discriminantes e reduzir o tempo gasto no cálculo das saliências, 
utiliza informações provenientes dos agrupamentos de características, de forma a alterar a topologia da rede neural em que se baseia o seletor. Tais agrupamentos podem ser extraídos por meio da projeção (seleção manual ou aplicação do K-means sobre as características projetadas). No entanto, sabe-se que a seleção manual não garante padronização alguma e o algoritmo $K$ means, dependendo da complexidade do espaço original de amostras, pode convergir a ótimos locais. Em ambos os casos, corre-se o risco de alimentar o seletor com um conjunto inconsistente de dados e, por consequência, produzir um subconjunto de características que não contribua para projeções mais representativas.

Uma maneira encontrada para evitar a formação de agrupamentos inconsistentes é implementar um mecanismo de agrupamento que seja mais robusto e imune a convergência em ótimos locais. Tal mecanismo foi desenvolvido por Bandyopadhyay [Bandyopadhyay and Maulik 2002] combinando Algoritmos Genéticos (AGs) e K-means de modo a evitar soluções sub-ótimas (ótimos locais). Um outro benefício da implementação de tal método é que, ao gerar agrupamentos sobre características (ao contrário de instâncias), este pode ser também utilizado como um seletor de características ao se considerar que características agrupadas indicam características correlacionadas, passíveis de serem descartadas. Dessa forma, pode-se utilizar apenas algumas amostras de cada grupo para compor o subconjunto selecionado.

\subsection{Organização do Trabalho}

Esta dissertação é composta por este capítulo de introdução seguido por mais cinco capítulos, assim organizados:

- No Capítulo 2 é abordada a seleção de características, visto que este é o tema principal deste trabalho. Destacam-se os seguintes conceitos: maldição da dimensionalidade, passos principais para o processo de seleção, alguns métodos de seleção e formas de avaliação dos subconjuntos selecionados.

- No Capítulo 3 são apresentados conceitos fundamentais para o desenvolvimento deste trabalho. Inicia-se com as projeções de dados multidimensionais, destacando as técnicas que foram utilizadas, a medida de silhueta (responsável pela avaliação das projeções) e as ferramentas, PEx e PEx-Image, usadas para gerar as projeções. Em seguida, apresentamse conceitos de agrupamento, destacando-se os algoritmos K-means e KGA-clustering e também o algoritmo de Hruschka [Hruschka and Covões 2005], capaz de estimar o número correto de agrupamentos. 
- No Capítulo 4 apresenta-se a abordagem de seleção de características baseada em projeção de dados multidimensionais proposta neste trabalho e detalhe-se o aprimoramento realizado no seletor por saliência baseado em rede neural $M L P$. Além disso, são descritos os conjuntos de imagens utilizados neste trabalho, juntamente com as características que foram extraídas.

- No Capítulo 5 apresentam-se os experimentos realizados, ilustrando os principais aspectos da abordagem proposta.

- Finalmente, no Capítulo 6 são apresentadas as considerações finais para este trabalho, suas principais contribuições para a seleção de características, limitações e propostas de trabalhos futuros. 
Capítulo 2

\section{Seleção de Características}

\subsection{Considerações Iniciais}

Nas atividades de consulta por similaridade, reconhecimento de padrões e mineração de dados (classificação, agrupamentos e projeções), cada instância (neste trabalho, imagens) do conjunto de dados é geralmente representada por um conjunto de atributos numéricos, organizados no que comumente chamamos de vetor de características. Estas características podem ser extraídas por meio de diversos extratores, que são algoritmos de processamento de imagens que procuram identificar atributos visuais (normalmente cor, forma ou textura) e traduzi-los em atributos numéricos. Alguns extratores geram características mais relevantes ${ }^{1}$ para determinado tipo de imagem, outros já não conseguem gerar características que diferenciam adequadamente categorias de imagens. Em outros casos, ao se utilizar características geradas por vários extratores, ou até mesmo por apenas um, é possível haver características correlacionadas, as quais não contribuem para a representação das instâncias.

Diante da existência de características correlacionadas ou com baixo poder discriminatório no conjunto de dados, surge a necessidade de selecionar as características mais adequadas, minimizando o problema da alta dimensionalidade, conhecido como maldição da dimensionalidade [Bellman 1957], e melhorando a eficiência e a eficácia das tarefas que utilizarão o conjunto de dados. A redução da dimensionalidade é possível visto que a maioria dos conjuntos de dados reais não obedecem às propriedades de uniformidade (conjuntos cujos valores dos atributos são distribuídos de maneira uniforme ou aleatória) e independência (conjuntos cujos valores dos atributos são independentes entre si), gerando correlações entre os atributos. Quando atributos estão correlacionados existe um mapeamento tal que o valor de um deles pode ser

\footnotetext{
${ }^{1}$ De forma geral, a relevância de uma característica é determinada por sua capacidade de diferenciar elementos de classes distintas.
} 
determinado diretamente pelo(s) outro(os), ou há um número reduzido de valores que ele pode assumir [Sousa 2006].

Existem duas abordagens para a redução da dimensionalidade: extração de características e seleção de características [Jain et al. 2000]. A extração de características consiste em criar novas características a partir de transformações e combinações das características do espaço original. A seleção de características, como o próprio nome diz, procura selecionar, segundo um determinado critério, o subconjunto mais relevante do conjunto de características original. Este capítulo trata da segunda abordagem, seleção de características, visto ser este o tema principal deste trabalho, destacando os seguintes conceitos: a maldição da dimensionalidade, os passos principais de um processo de seleção de características, alguns métodos de seleção e medidas de avaliação dos subconjuntos selecionados.

\subsection{Maldição da Dimensionalidade}

Dimensão se refere a quantidade de atributos (características) que representam as imagens. Quando o número de atributos do conjunto de dados é grande (alta dimensionalidade), ocorre a degradação da performance das técnicas desenvolvidas para armazenamento, manipulação e análise de dados, assim como do processo de descoberta de conhecimento, além de elevar o custo computacional para a manipulação dos dados.

Em mineração de dados, a maldição da dimensionalidade é um problema tanto em atividades preditivas quanto em descritivas. Por exemplo, a grande quantidade de atributos aumenta o espaço de busca, reduzindo a precisão na discriminação de objetos de classes distintas [Aggarwal 2005]. Segundo Jain et al. [Jain et al. 2000] existe uma relação entre a quantidade de amostras, o número de atributos e a complexidade dos classificadores. Resultados empíricos mostraram que deve-se utilizar no mínimo um número de amostras por classe dez vezes maior que a dimensionalidade. Considerando as atividades descritivas, objetos em um espaço de alta dimensionalidade tendem a ficar mais esparsos e as distâncias entre pares de objetos tendem a apresentar valores muito próximos uns dos outros, o que dificulta a detecção eficiente de agrupamentos [Aggarwal and Yu 2002].

Diante da necessidade de se minimizar os efeitos da maldição da dimensionalidade, percebese a importância da redução da dimensionalidade antes da execução de outras atividades. Maiores detalhes sobre a maldição da dimensionalidade podem ser encontrados em [Bellman 1957; Jain et al. 2000; Korn et al. 2001]. A seção 2.3 apresenta conceitos importantes sobre seleção de características, enquanto a seção 2.4 descreve os mecanismos mais comumente usados para a avaliação das mesmas. 


\subsection{Seleção de Características}

O processo de seleção de características consiste em: dado um conjunto original de características $Y$, de dimensão $m$, selecionar com o intuito de atingir um objetivo, um subconjunto $X, X \subset Y$. O alcance do objetivo é medido por uma função critério, representada por $J(X)$. Geralmente, o objetivo em um problema de seleção de características pode ser: (1) maximizar o valor de uma função critério para um subconjunto com $d$ características; (2) encontrar o menor subconjunto de forma que a função critério não ultrapasse um valor dado; (3) maximizar o valor da função critério e minimizar o tamanho do subconjunto [Kudo and Sklansky 2000].

Idealmente, seleção de características procura encontrar um subconjunto ótimo em um conjunto que possua características irrelevantes ou redundantes. Entretanto, para se ter garantia de uma solução ótima é preciso realizar uma busca exaustiva, o que na maioria dos casos é inviável computacionalmente. Isso leva à utilização de heurísticas para realizar a seleção. Independentemente do método utilizado, o processo de seleção de características possui quatro passos principais [Liu and Yu 2005], os quais são discutidos detalhadamente na próxima subseção.

\subsubsection{Passos Principais do Processo de Seleção de Características}

Liu e Yu [Liu and Yu 2005] definem quatro passos principais que são realizados durante o processo de seleção de características: a geração dos subconjuntos de características candidatos, a avaliação dos subconjuntos, a definição do critério de parada e a validação dos resultados. A geração dos subconjuntos candidatos consiste em selecionar subconjuntos de características e apresentá-los para posterior avaliação. O processo de escolha da técnica de geração dos subconjuntos engloba a definição do estado inicial dos subconjuntos de características (conjunto completo, vazio ou definido aleatoriamente) e a definição da estratégia de busca que será utilizada:

- Forward Selection: inicia-se com o conjunto vazio e adiciona características sucessivamente.

- Backward Selection: inicia-se com o conjunto completo e elimina características sucessivamente.

- Bidirectional Selection: inicia-se com um conjunto vazio e um conjunto completo e, características vão sendo adicionadas e eliminadas simultaneamente.

Após definir o estado inicial do subconjunto, deve-se definir a estratégia de busca. Como a busca exaustiva é inviável para grandes conjuntos de características, visto que para um conjunto 
com $m$ características têm-se $2^{m}$ subconjuntos candidatos, utilizam-se diferentes heurísticas para a realização da busca:

- Busca Completa: consegue encontrar a solução ótima, de acordo com o critério de avaliação usado, sem percorrer todo o espaço de busca. Utilizam-se funções heurísticas para reduzir o espaço de busca, de forma que não avalie todos os subconjuntos candidatos. Entretanto, também é uma estratégia cara computacionalmente.

- Busca Sequencial: corre-se o risco de não encontrar a solução ótima, entretanto, é rápida e fácil de implementar. Possui três abordagens principais: sequential forward selection, sequential backward elimination e bidirectional selection, conforme definido anteriormente.

- Busca Aleatória: inicia-se com um subconjunto gerado aleatoriamente. Posteriormente, consideram-se duas possíveis ações: realizar uma busca sequencial partindo do conjunto aleatório ou, gerar o próximo subconjunto de maneira totalmente aleatória, ou seja, o subconjunto atual não aumenta nem diminui a partir do subconjunto anterior. Esse tipo de busca tem a vantagem de ser menos suscetível a ficar presa a ótimos locais.

O segundo passo do processo de seleção de características é a avaliação dos subconjuntos. Assim, após a geração dos subconjuntos candidatos é necessário avaliá-los, segundo algum critério, para selecionar um deles. Devido à importância deste passo para o processo de seleção de características, ele será apresentado com mais detalhes na seção 2.4.

O terceiro passo consiste na definição do critério de parada, o qual determina quando a busca deve parar. Muitas vezes o critério de parada é dependente da aplicação. Como exemplos de critérios de parada usados, têm-se [Liu and Yu 2005]: (a) a varredura completa do espaço de busca; (b) o alcance de algum limite pré-determinado (como, por exemplo, o número de iterações); (c) novas inserções ou remoções não tornam os subconjuntos de características mais relevantes; (d) o subconjunto de características alcança qualidade suficiente de acordo com algum critério de avaliação. Por fim, o último passo do processo de seleção é a validação dos resultados obtidos pelo método de seleção de características. Esse processo dependerá da tarefa que utilizará as características selecionadas como, por exemplo, classificação, agrupamento ou projeção.

Após a definição dos principais passos realizados durante o processo de seleção de características, será apresentado, na subseção seguinte, alguns métodos de seleção existentes, conforme a taxonomia definida por Jain e Zongker [Jain and Zongker 1997]. 


\subsubsection{Métodos de Seleção de Características}

Existem várias revisões na literatura que abordam os diferentes métodos de seleção de características [Jain and Zongker 1997; Kudo and Sklansky 2000; Liu and Yu 2005]. Seguindo a taxonomia apresentada em 1997 por Jain e Zongker [Jain and Zongker 1997], os métodos de seleção de características podem ser divididos conforme o diagrama observado na Figura 2.1.

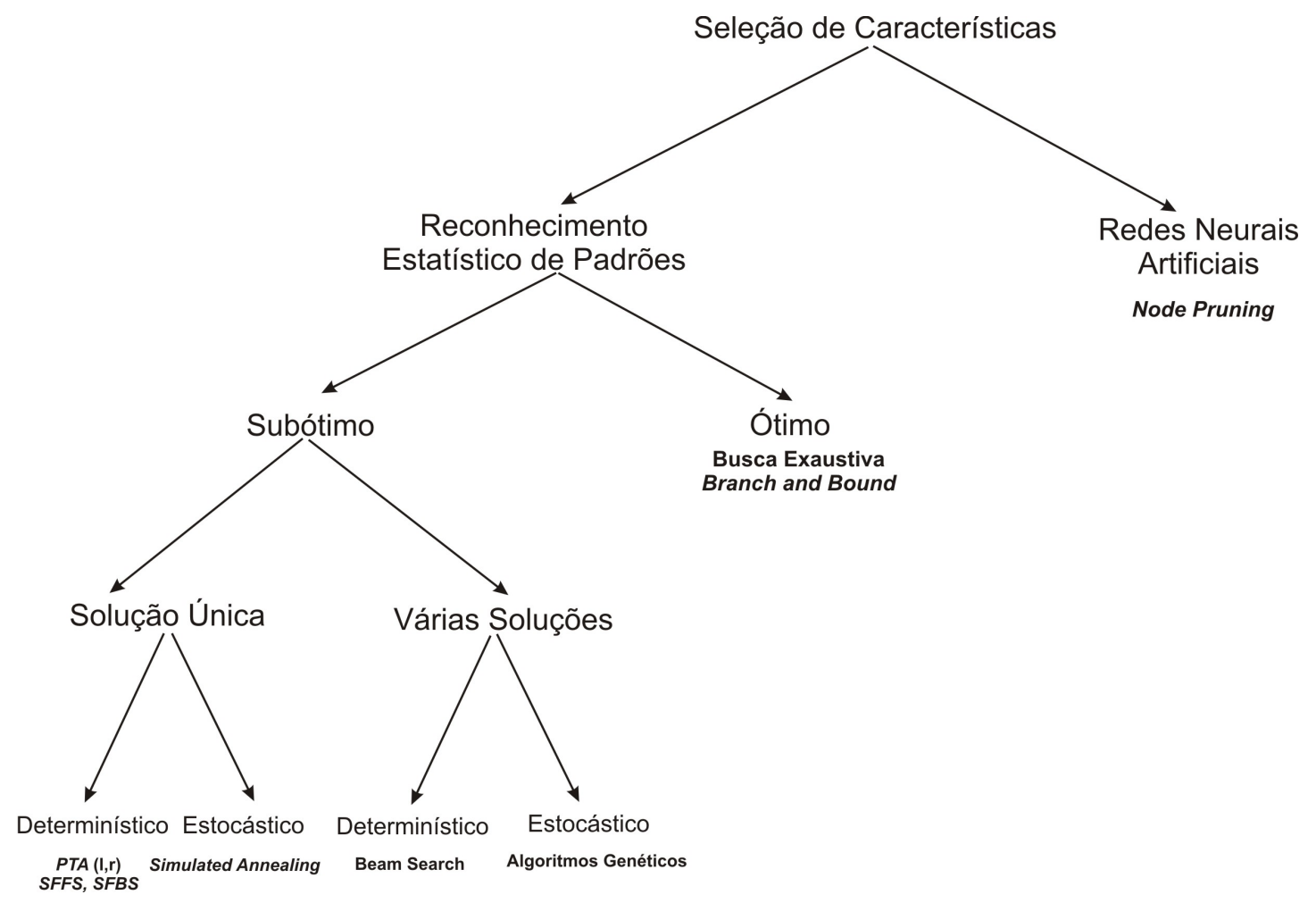

Figura 2.1: Taxonomia dos métodos de seleção de características apresentada por Jain e Zongker [Jain and Zongker 1997].

Os métodos "ótimos" possuem a garantia de encontrar a melhor solução, entretanto, possuem um alto custo computacional. Já os métodos "sub-ótimos" não possuem essa garantia. A abordagem "solução única" trabalha apenas com um subconjunto de características durante o processo, enquanto que a abordagem "várias soluções" trabalha com vários subconjuntos ao mesmo tempo. Por fim, os algoritmos "determinísticos", a cada execução, sempre chegam a mesma solução para uma determinada entrada e, algoritmos "estocásticos" podem obter soluções diferentes, em execuções diferentes, para a mesma entrada, pois realizam operações aleatórias. A seguir, apresenta-se uma descrição mais detalhada das categorias, incluindo exemplos de algoritmos. 


\section{Métodos Ótimos}

Quando se trata da obtenção do melhor subconjunto de características, deve-se realizar uma Busca Exaustiva, pois esta avalia todas as possíveis combinações de características para obter a solução. Assim, para um conjunto original com $m$ características têm-se $2^{m}$ subconjuntos candidatos. Diante disso, esse algoritmo apresenta complexidade exponencial, o que o torna inviável computacionalmente, mesmo para conjuntos não muito grandes.

Um algoritmo capaz de chegar à solução ótima sem verificar todas as possibilidades é o Branch and Bound, proposto originalmente em [Narendra and Fukunaga 1977]. Esse método utiliza uma árvore de busca onde a raiz representa o conjunto de características original $Y$, os outros nós representam os subconjuntos de $Y$ e as folhas representam todos os subconjuntos possíveis de tamanho $d$.

Quando a função critério $J$ utilizada no Branch and Bound é monotônica não é necessário percorrer toda a árvore para encontrar a solução ótima, visto que ramos inteiros podem ser eliminados sem prejudicar a obtenção da solução. Entretanto, no pior caso, o Branch e Bound apresenta complexidade exponencial. Ressalta-se que uma função é dita monotônica se puder ser classificada como crescente, estritamente crescente, decrescente e estritamente decrescente. Por exemplo, se $J(X \cup Z) \geq J(X)$ para todo $X, Z \subseteq Y$ temos uma função monotônica crescente [Campos 2001].

Vários aperfeiçoamentos foram realizados no Branch and Bound original para melhorar sua eficiência como, por exemplo, o Branch and Bound Ordenado [Narendra and Fukunaga 1977] (as características são ordenadas de acordo com a função critério durante a construção da árvore), o Branch and Bound Rápido [Somol et al. 2000] (utiliza previsões da função critério e algumas decisões são tomadas a partir dessas previsões), o Branch and Bound com Previsão Parcial [Somol et al. 2001] (utiliza a mesma técnica de previsão do Branch and Bound Rápido, mas, apenas para a ordenação das características) e o Branch and Bound Adaptativo [Nakariyakul and Casasent 2007] (utiliza várias estratégias: previsão, única ordenação antes do percurso pela árvore, obtenção de solução inicial por outro algoritmo, início do percurso a partir de um determinado nível da árvore e busca da direita para a esquerda).

\section{Métodos Determinísticos de Solução Única}

Esse grupo de métodos, também conhecidos como métodos sequenciais, iniciam com uma única solução (único subconjunto de características) e adicionam ou removem características, a cada iteração, até atingir um critério de parada. As características são escolhidas de acordo com a função critério $J($.$) . Os métodos sequenciais são caracterizados pelas abordagens de$ busca forward e backward, conforme definidas na subseção 2.3.1. 
Como exemplos de algoritmos que utilizam essas abordagens têm-se: sequential forward selection (SFS) e sequential backward selection (SBS). Estes são os algoritmos mais simples, pois adicionam (ou removem) uma característica ao subconjunto a cada iteração, de acordo com a função critério. O processo é repetido até o subconjunto atingir o tamanho $d$. Com o objetivo de melhorar a eficiência do $S F S$ e $S B S$, desenvolveu-se o algoritmo plus-l take-away$r(l, r)$, conhecido como PTA $(l, r)$, no qual, a cada iteração, adicionam-se $l$ características ao subconjunto, utilizando o $S F S$ e, removem-se $r$ características do subconjunto, utilizando o $S B S$. Os valores de $l$ e $r(l \neq r)$ são definidos pelo usuário.

Devido à dificuldade em se definir os melhores valores de $l$ e $r$ antes da execução do algoritmo PTA $(l, r)$, foram propostos os algoritmos sequential floating forward selection (SFFS) e sequential floating backward selection (SFBS) [Pudil et al. 1994]. Semelhante ao PTA(l,r), em cada iteração do $S F F S$, uma característica é adicionada e zero ou mais características são removidas enquanto forem encontrados subconjuntos melhores. Já no $S F B S$, uma característica é removida e zero ou mais características são adicionadas enquanto forem encontrados subconjuntos melhores. Uma comparação dos algoritmos citados pode ser encontrada em [Kudo and Sklansky 2000].

\section{Métodos Estocásticos de Solução Única}

Correspondem ao conjunto de métodos que resultam em apenas um subconjunto de características e que, a cada execução, podem gerar uma resposta diferente para a mesma entrada, por utilizarem processos aleatórios. Como exemplo de algoritmo pertencente a esta classe temse o Simulated Annealing, o qual é um algoritmo de otimização que consiste em uma técnica de busca local probabilística e faz analogia com a termodinâmica [Kirkpatrick et al. 1983]. Esse algoritmo começa sua busca a partir de uma solução inicial qualquer, chamada de $s$. Em cada iteração do algoritmo, o valor da solução $s$ é substituído por outra solução, escolhida de acordo com uma função objetivo e com uma variável $T$, chamada de temperatura. Quanto maior o valor de $T$, maior a componente aleatória incluída na próxima solução escolhida. À medida que o algoritmo progride, o valor de $T$ é decrementado, começando o algoritmo a convergir para uma solução ótima.

\section{Métodos Determinísticos de Várias Soluções}

Correspondem a classe de métodos que sempre chegam à mesma solução para uma dada entrada (determinístico) e que trabalham com mais de uma solução, ou seja, mais de um subconjunto de características. Normalmente, estes métodos tratam o espaço de subconjuntos como um grafo, onde cada vértice corresponde a um subconjunto e existe uma aresta entre 
dois vértices se o subconjunto de características representado por um dos vértices é um superconjunto do subconjunto representado pelo outro vértice. A busca pelo melhor subconjunto é realizada por meio de um algoritmo de busca em grafo [Jain and Zongker 1997]. Como exemplos de métodos desta categoria têm-se o search best-first e sua versão mais restritiva beam search.

\section{Métodos Estocásticos de Várias Soluções}

Métodos estocásticos de várias soluções são aqueles que lidam com vários subconjuntos de características, os quais possuem uma boa avaliação pela função critério. Além disso, a cada vez que são executados, esses métodos podem fornecer um conjunto de soluções diferente da anterior, por utilizarem processos aleatórios. Esta classe de métodos engloba o uso de Algoritmos Genéticos (AGs) para a seleção de características.

Em 1989, Siedlecki e Sklansky [Siedlecki and Sklansky 1989] introduziram os AGs para a seleção de características e, desde então, eles vêm sendo bastante usados devido à sua habilidade de procurar por soluções ótimas sem percorrer todo o espaço de busca e, ao fato de serem menos suscetíveis, que as técnicas de busca local, a ficarem presos em soluções que são ótimos locais. Além disso, Kudo e Sklansky [Kudo and Sklansky 2000] verificaram que os AGs superam em eficiência e eficácia os métodos Branch and Bound, SFS, SBS, Floating Search e suas variações para problemas de seleção de características de grande escala, onde o número de características no conjunto inicial é maior ou igual a 50. Em seguida, apresentam-se conceitos iniciais sobre AGs e o uso de AGs para a seleção de características.

- Algoritmos Genéticos: São métodos de busca ou otimização não determinísticos inspirados no conceito de evolução natural e na genética [Said 2005]. No espaço de busca do problema, cada solução candidata é considerada como um indivíduo e é representada por uma cadeia de símbolos, chamada cromossomo. Cada símbolo presente no cromossomo é chamado de gene.

Inicialmente, após definir uma representação para os indivíduos, uma população inicial com $T_{p}$ (onde $T_{p}$ corresponde ao tamanho da população) indivíduos é gerada aleatoriamente. Em seguida, cada indivíduo da população é avaliado através de uma função objetivo para obter a sua aptidão (fitness) e, caso atinja o critério de parada o ciclo é terminado. Senão, um subconjunto de indivíduos será selecionado e passará por um processo de reprodução (cruzamento e mutação), dando origem a uma nova população. Os indivíduos descendentes são avaliados e $T_{p}$ indivíduos da população "pais+filhos" sobreviverão. Então, verifica-se, dentre os sobreviventes, se satisfazem o critério de parada. 
Caso não satisfaçam, o processo de seleção para posterior reprodução, avaliação e seleção de sobreviventes continuará até atingir o critério de parada. Quando o critério de parada for atingido, dará origem a uma população final de indivíduos mais aptos, ou seja, a(s) melhor(es) solução(ões) para o problema será(ão) obtida(s).

- Seleção de Características por meio de Algoritmos Genéticos: Em AGs, cada subconjunto de características pode ser codificado como uma string binária ou um vetor de valores binários, de tamanho $m$ ( $m$ é o número total de características), chamado cromossomo [Siedlecki and Sklansky 1989]. Um cromossomo $a=a_{1}, a_{2}, \ldots, a_{m}$ representa um subconjunto de características, onde $a_{i}$ assume valor 0 se a $i$-ésima característica foi removida do subconjunto e 1 se a $i$-ésima característica está presente no subconjunto, conforme observado na Figura 2.2.

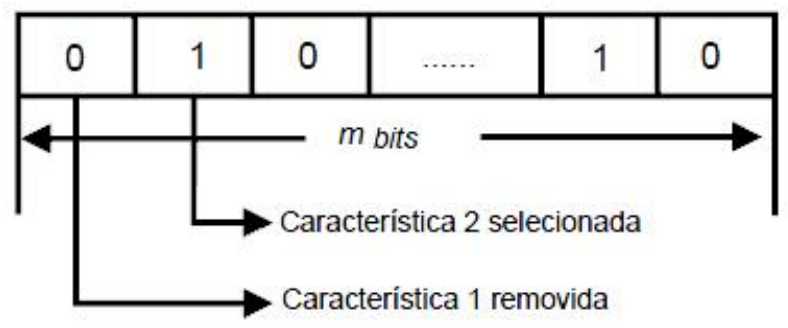

Figura 2.2: Representação de cromossomo em seleção de características.

Inicialmente, cria-se uma população de cromossomos aleatoriamente. Em seguida, cada cromossomo é avaliado através de uma função critério para obter sua aptidão, a qual determina se o cromossomo irá sobreviver para a próxima geração ou não. A partir de mutações ou cruzamentos dos cromossomos atuais criam-se novos cromossomos. Após várias iterações obtém-se um conjunto de soluções. Como o processo utilizado contém operações probabilísticas e aleatórias, o algoritmo pode chegar a soluções diferentes, quando aplicado ao mesmo conjunto de entrada, em momentos diferentes.

\section{Redes Neurais Artificiais}

As Redes Neurais Artificiais (RNAs) vêm sendo usadas para a seleção de características, conforme visto em vários trabalhos [Battiti 1994; Mao and Jain 1995; Leray and Gallinari 1999; Santos and Batista Neto 2007], quando a única fonte de informação disponível são os dados de treinamento. Além disso, como as RNAs não fazem qualquer suposição prévia sobre as funções de distribuição de probabilidade dos dados, elas passaram a ser utilizadas para a seleção de 
características como alternativa aos métodos estatísticos, evitando assim suas condições restritivas [Castellano and Fanelli 2000].

Redes neurais artificiais são sistemas computacionais, formados por uma ou mais camadas de elementos interconectados, chamados neurônios, que recebem dados de entrada, que são processados em conjunto pelos neurônios, obtendo-se uma saída. Inicialmente, as RNAs foram inspiradas no funcionamento do cérebro humano e, posteriormente foram incluídos conceitos de estatística e processamento de sinais.

O primeiro modelo matemático de neurônio artificial foi proposto por MacCulloch e Pitts [MacCulloch and Pitts 1943] e foi inspirado nas propriedades fisiológicas dos neurônios biológicos. Possui como características entradas binárias e função de ativação limiar. Posteriormente, o neurônio do tipo MacCulloch-Pitts foi generalizado, resultando no neurônio apresentado na Figura 2.3 [Haykin 1999].

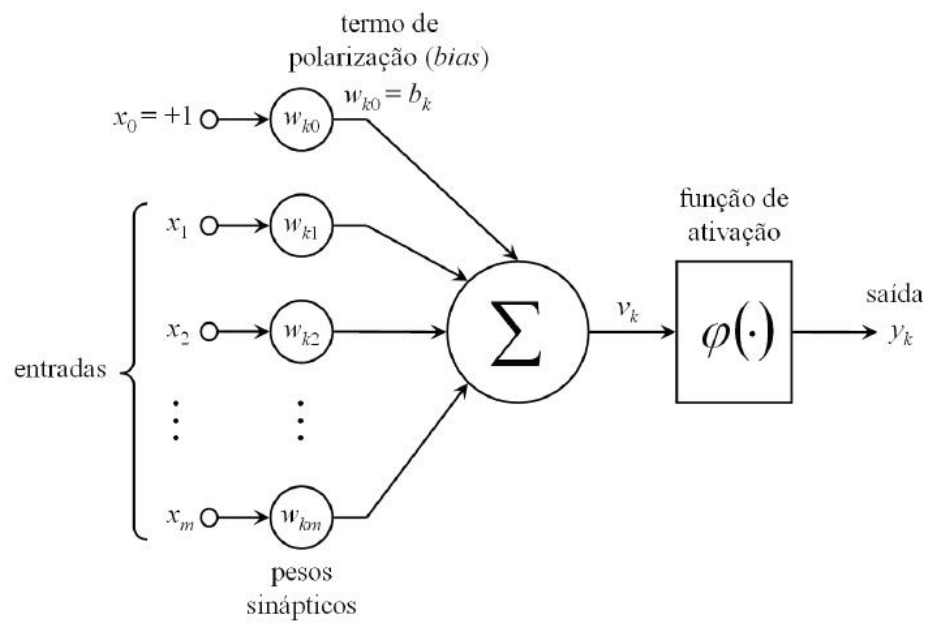

Figura 2.3: Modelo de um neurônio artificial.

O neurônio artificial recebe uma entrada, de $m$ dimensões, representada por $x_{1}, x_{2}, \ldots, x_{m}$. Há também um conjunto de pesos $w_{k 1}, w_{k 2}, \ldots, w_{k m}$, que representam o conhecimento adquirido pela rede. O termo de polarização (bias), que se comporta como o peso de uma entrada extra de valor 1 , é responsável pelo hiperplano gerado pelo neurônio não passar pelo ponto de origem do espaço. Os valores de entrada são multiplicados pelos pesos e somados, resultando na equação 2.1 .

$$
v_{k}=\sum_{j=0}^{m}\left(x_{j} \cdot w_{k j}\right)
$$


O valor $v_{k}$ será a entrada da função de ativação. Existem diferentes funções de ativação, sendo que cada uma é adequada para um tipo de rede neural. Como exemplos, tem-se a função limiar, usada no neurônio MacCulloch-Pitts e apresentada na equação 2.2 e, as funções sigmoidais, que têm como exemplo a função logística apresentada na equação 2.3, onde o parâmetro $a$ representa a suavidade da curva.

$$
\begin{aligned}
& \varphi(v)= \begin{cases}1, & \text { se } v>0 \\
0, & \text { se } v \leq 0\end{cases} \\
& \varphi(v)=\frac{1}{1+\exp (-a . v)}
\end{aligned}
$$

As funções sigmoidais são as mais usadas em redes neurais por serem limitadas, monotônicas e apresentarem comportamento entre linear e não linear. Além disso, possuem derivada contínua, uma exigência para o uso do algoritmo de aprendizado Backpropagation [Rumelhart and McClelland 1986], utilizado em redes neurais de múltiplas camadas.

Inicialmente, foram desenvolvidas redes neurais de camada única, chamadas de Perceptron [Rosenblatt 1958], na qual a camada de entrada é ligada diretamente à camada de saída e o treinamento é realizado através da regra delta, onde busca-se minimizar o erro obtido pela diferença entre a saída da rede e a saída desejada. Entretanto, a rede Perceptron de camada única é capaz de chegar a soluções eficazes apenas se aplicada a conjuntos de treinamento linearmente separável, ou seja, conjuntos cujo hiperplano separa completamente elementos de classes distintas.

Diante disso, foram desenvolvidas as redes Perceptron de Múltiplas Camadas (Multilayer Perceptron - MLP, em inglês), que possuem uma ou mais camadas intermediárias, chamadas de camadas ocultas, e permitem a geração de soluções para conjuntos de treinamento não linearmente separáveis. As redes $M L P$ geralmente são treinadas pelo algoritmo Backpropagation ou suas variações.

O Backpropagation é um algoritmo iterativo e possui duas etapas. Na primeira etapa realizase a propagação, onde os valores de entrada são processados, camada por camada, até obter a resposta na camada de saída. O erro da rede é determinado pela diferença entre a resposta gerada pela rede e a resposta desejada. Na segunda etapa ocorre a retropropagação, onde o erro é transmitido da camada de saída até a primeira camada oculta e as variações dos pesos são determinadas. Essas duas etapas são repetidas até que atinja o critério de parada. Maiores detalhes podem ser encontrados em [Haykin 1999]. 
As redes Perceptron de Múltiplas Camadas podem ser usadas para seleção de características, através do cálculo de uma medida de saliência, conforme explicado a seguir. Como exemplos de algoritmos que usam medida de saliência em redes neurais têm-se o Node Pruning [Mao et al. 1994] que é bastante conhecido e o algoritmo mais recente, proposto por Santos [Santos and Batista Neto 2007].

- Medida de saliência em uma rede neural $\boldsymbol{M L P}$ : Garson [Garson 1991] propôs o cálculo de uma medida de saliência para cada entrada de uma rede neural $M L P$, após o seu treinamento, que se mostrou viável para a seleção de características quando comparada a métodos tradicionais [Nath et al. 1997]. Através da medida de saliência é possível determinar a relevância das características sem repetidos treinamentos.

Inicialmente, o método para o cálculo da saliência foi proposto para ser aplicado em redes MLP's de uma camada oculta e uma saída [Garson 1991] [Nath et al. 1997]. Depois, Santos [Santos and Batista Neto 2007] estendeu o método para diversas saídas, onde se faz uma estimativa da importância de cada entrada baseada no custo dos diferentes caminhos de conexões possíveis até as saídas.

Para determinar a medida de saliência, calcula-se, primeiramente, um fator de normalização $N_{o}$, para cada neurônio oculto $o$, o qual consiste na soma do módulo de suas conexões $w_{e, o}^{\text {camadaOculta }}$, onde o índice $e$ corresponde ao número do nó de entrada:

$$
N_{o}=\sum_{e}\left|w_{e, o}^{\text {camadaOculta }}\right|
$$

Cada combinação de caminhos possíveis (acrescentando-se à notação a variável $s$ para neurônios de saída) retorna um determinado valor $w_{e, o, s}^{*}$, baseado no peso normalizado da entrada e no valor do peso de saída:

$$
w_{e, o, s}^{*}=\frac{\left|w_{e, o}^{\text {camadaOculta }}\right|\left|w_{o, s}^{\text {camadaDeSaida }}\right|}{N_{o}}
$$

Assim, a medida de saliência $S_{e, s}$ da entrada $e$ para a saída $s$ é dada pela equação 2.6.

$$
S_{e, s}=\sum_{o} w_{e, o, s}^{*}
$$

Caso diversas saídas sejam consideradas, a saliência total STe da entrada e pode ser calculada pela equação 2.7, conforme proposto em [Santos and Batista Neto 2007]: 


$$
S T e=\sum_{s} \frac{S_{e, s}}{\sum_{f} S_{f, s}}
$$

Dessa forma, cada característica terá uma medida de saliência. Uma forma de realizar a seleção do subconjunto de características é excluir aquela com menor saliência e retreinar a rede. Este processo continua até que se obtenha apenas um conjunto de características do tamanho desejado. A Figura 2.4 mostra a topologia tradicional de um seletor por saliência baseado em $M L P$. A entrada em cada neurônio de entrada é uma característica, e cada qual se conecta a todos os neurônios da camada oculta.

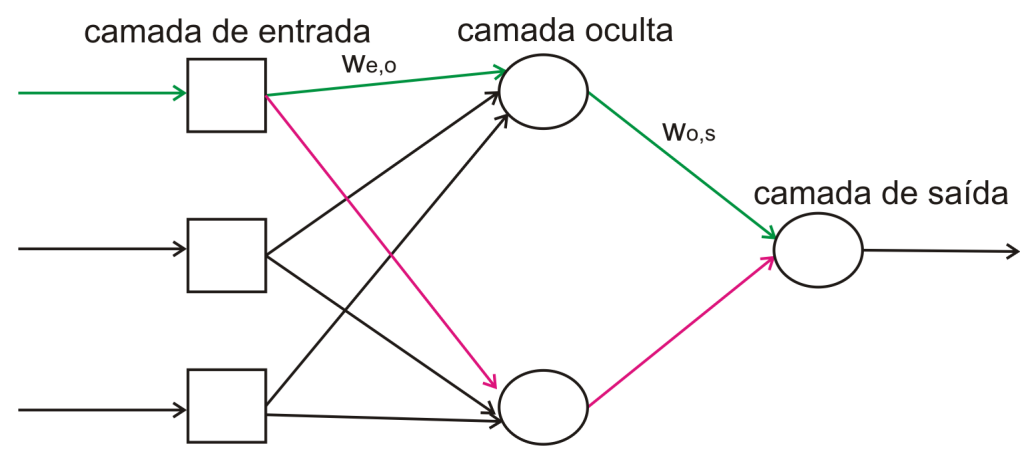

Figura 2.4: Topologia tradicional de um seletor de características por saliência baseado em rede neural $M L P$.

Seja $m$ o número de características conectadas à entrada, o o número de neurônios da camada oculta e $s$ o número de saídas da rede (cada classe de imagem, por exemplo). Então, o número de conexões da rede é da ordem de $m o+o s$. Se considerarmos $o$ um valor proporcional à $m$ (digamos, $o=m / 2$ ), então teremos que o cálculo das medidas de saliência final do seletor é da ordem de $m^{2}$.

O seletor por saliência proposto por Santos [Santos and Batista Neto 2007] foi aplicado à segmentação de imagens de cenas naturais. Inicialmente, as características foram extraídas das imagens por meio de diferentes métodos de extração gerando vetores de alta dimensionalidade. Diante disso, a seleção das características mais relevantes foi feita pelo seletor por saliência baseado em rede neural $M L P$. Os subconjuntos selecionados foram usados na segmentação de imagens, obtendo resultados satisfatórios. 


\subsection{Avaliação dos Subconjuntos de Características Sele- cionados}

A avaliação dos subconjuntos de características é muito importante para o processo de seleção, pois é responsável pela qualidade do subconjunto selecionado. A avaliação é feita por meio de uma função critério, que normalmente recebe como entrada um conjunto de números inteiros, que representam as características selecionadas e retornam um valor real. Por exemplo, se for um problema de maximização, quanto maior o valor retornado pela função critério, melhor o subconjunto de características.

Existem dois tipo de funções critério: Dependentes e Independentes [Liu and Yu 2005]. As funções critério dependentes fazem a avaliação com base em um algoritmo específico de reconhecimento de padrões, utilizando a própria medida de performance do algoritmo para selecionar as características. Os modelos de seleção que utilizam essa forma de avaliação são chamados de Wrapper [Blum and Langley 1997].

$\mathrm{Na}$ seleção de características supervisionada pode-se, por exemplo, utilizar a taxa de acerto de um classificador para avaliar o subconjunto de características. Como exemplos de métodos para estimar a taxa de acerto de um classificador têm-se [Kohavi 1995]:

- Holdout: método que divide a base de dados em dois subconjuntos, um de treino (com $70 \%$ dos elementos, por exemplo) e outro de teste (com o restante dos elementos), sem repetição de elementos. O classificador é treinado com o conjunto de treino e a taxa de acerto é estimada com o conjunto de teste.

- K-fold cross-validation: método que divide a base de dados em $K$ partições de aproximadamente o mesmo tamanho, sem repetição de elementos. Em seguida, são realizados $K$ testes, sendo que em cada um, uma partição é usada como conjunto de teste e as restantes são usadas como conjunto de treinamento.

Na seleção de características não supervisionada, a qualidade do subconjunto de características é medida pela qualidade dos agrupamentos gerados, de acordo com algum critério de avaliação. Existem diversos critérios heurísticos para avaliar a qualidade do resultado de um algoritmo de agrupamento como, por exemplo, cluster compactness, scatter separability e maximum likelihood [Liu and Yu 2005].

Por outro lado, as funções critério independentes avaliam a qualidade do subconjunto de características sem utilizar um algoritmo de reconhecimento de padrões, buscando explorar as características intrínsecas dos dados como, por exemplo, as medidas de distância (ou de separabilidade entre classes), de informação, de dependência (correlação ou similaridade) e de 
consistência. Os modelos de seleção que utilizam esse tipo de avaliação são chamados de Filtro [Blum and Langley 1997]. A seguir apresentam-se alguns exemplos de medidas estatísticas de distância para verificar a separabilidade entre classes:

- Distância de Mahalanobis [Mahalanobis 1936]: Sejam $M_{c}$ e $C_{c}$ o vetor de média e a matriz de covariância da classe $c$, respectivamente. A distância de Mahalanobis $M h_{i, j}$ entre as classes $i$ e $j$ é dada por:

$$
M h_{i, j}=\frac{1}{8} \cdot\left(M_{j}-M_{i}\right)^{T} \cdot\left(\frac{C_{i}+C_{j}}{2}\right)^{-1}
$$

- Distância de Bhattacharrya [Bhattacharyya 1943]: é bastante utilizada quando há duas classes e depende da distância de Mahalanobis. Considerando que |.| represente o determinante da matriz, a distância de Bhattacharrya $B_{i, j}$ entre as classes $i$ e $j$ é dada por:

$$
B_{i, j}=M h_{i, j}+\frac{1}{2} \ln \cdot\left(\frac{\left|\frac{C_{i}+C_{j}}{2}\right|}{\sqrt{\left|C_{i}\right|\left|C_{j}\right|}}\right)
$$

Caso $C_{i}=C_{j}$, o segundo termo é igual a 0, resultando na Distância de Mahalanobis.

- Distância Jeffries-Matusita [Huber and Dutra 1998]: é uma medida que retorna um valor entre 0 e 2 e pode ser utilizada para qualquer número de classes. A distância JeffriesMatusita $J M_{i, j}$ é dependente da distância de Bhattacharrya e é dada por:

$$
J M_{i, j}=2 .\left(1-\exp \left(-B_{i, j}\right)\right)
$$

Quando se utilizam mais de duas classes somam-se as distâncias de todos os pares de classes ponderando pelas probabilidades a priori $P_{c}$, conforme mostrado a seguir:

$$
J M=2 . \sum_{c, l} P_{c} P_{l} J M_{c, l}
$$


Assim, quanto maior o valor obtido pela distância $J M$, melhor será o subconjunto de características.

\subsection{Considerações Finais}

A presença de características correlacionadas ou irrelevantes em um conjunto de dados pode prejudicar as atividades de reconhecimento de padrões, mineração de dados (classificação, agrupamentos, projeções) e/ou consultas por similaridade. Diante disso, métodos de seleção de características são fundamentais para melhorar a eficiência e a eficácia das atividades citadas, além de minimizar os problemas causados pela alta dimensionalidade.

O processo de seleção de um subconjunto de características ótimo é caracterizado pela busca do melhor subconjunto através de todas as combinações possíveis de características. Como a busca exaustiva é impraticável devido à complexidade exponencial, a maioria dos métodos de busca são baseados em heurísticas ou processos aleatórios. Ambos podem ser caracterizados por quatro passos principais: geração dos subconjuntos de características candidatos, avaliação dos subconjuntos, definição do critério de parada e validação dos resultados. Devido à importância do processo de avaliação para a obtenção de um bom subconjunto de características, foram apresentadas algumas medidas de avaliação.

Alguns métodos tradicionais de seleção de características, baseados na taxonomia de Jain e Zongker [Jain and Zongker 1997], foram apresentados, incluindo os métodos ótimos (Busca Exaustiva e Branch and Bound), os métodos determinísticos de solução única ( $S F S$, $S B S$, PTA, SFFS e $S F B S$ ), os métodos estocásticos de várias soluções (que utilizam Algoritmo Genético para a seleção de características) e as redes neurais artificiais (que utilizam medida de saliência para a seleção de características). Dentre essas categorias, duas foram utilizadas neste trabalho de mestrado: seletores baseados em redes neurais e em algoritmos genéticos, visto que apresentam bons resultados quando comparados aos métodos ótimos, principalmente porque se aplicam a casos reais, que envolvem vetores de características de alta dimensionalidade.

O próximo capítulo introduz alguns conceitos relacionados às técnicas e ferramentas de projeção de dados multidimensionais, além de aspectos de agrupamento de dados. Tais conceitos são muito importantes para o desenvolvimento deste trabalho. 


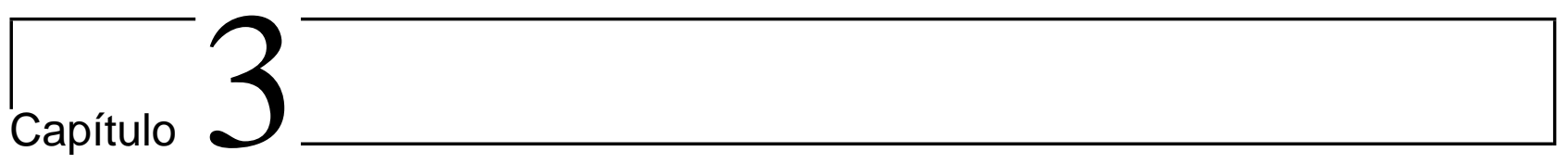

\section{Conceitos de Projeções e} Agrupamentos

\subsection{Considerações Iniciais}

A proposta de seleção de características apoiada por mineração visual de dados requer o conhecimento de técnicas e utilização de ferramentas de duas áreas de conhecimento, a saber: projeção de dados multidimensionais e agrupamento. A seção 3.2, além de conceituar a projeção de dados multidimensionais, descreve as técnicas utilizadas neste trabalho, um mecanismo capaz de quantificar a qualidade dos agrupamentos observados nas projeções e a ferramenta utilizada para a geração das projeções. A seção 3.3 descreve os métodos de agrupamento utilizados, juntamente com um método para estimar o número correto de agrupamentos.

\subsection{Projeção de Dados Multidimensionais}

Projeção de dados multidimensionais consiste no mapeamento de dados $m$-dimensionais em um espaço $p$-dimensional, com $p=\{1,2,3\}$ e $p<m$, preservando ao máximo as relações de distância existentes entre os dados, de forma a revelar algum tipo de similaridade ou correlação [Tejada et al. 2003]. Dessa forma, as técnicas de projeção idealmente buscam garantir que os pontos posicionados próximos no layout de saída representem dados similares de acordo com a distância escolhida, caso contrário, devem representar dados não relacionados ou pouco relacionados.

As técnicas de projeção são bastante utilizadas pois permitem a exploração e análise dos dados. Dentre suas inúmeras vantagens destacam-se a possibilidade de empregar a interação 
humana, com o auxílio de ferramentas gráficas, para identificar padrões que não são detectáveis por métodos clássicos de análise e, também permitem identificar grupos de elementos similares, relacionamentos entre grupos que compartilham fronteiras e elementos que pertencem a mais de um grupo.

Existem várias técnicas de projeção de dados na literatura [Cox and Cox 2000; Fodor 2002; Steyvers 2002; Paulovich 2008], as quais podem ser divididas em três grupos: Multidimensional Scaling (MDS), Force-Directed Placement (FDP) e Técnicas para Redução de Dimensionalidade [Paulovich 2008]. Devido às suas características, no desenvolvimento deste trabalho, utilizamos as seguintes técnicas para gerar as projeções: Classical Scaling (CS) [Torgerson 1952] e Sammon's Mapping (SM) [Sammon 1969], pertencentes ao grupo Multidimensional Scaling, e Least Square Projection (LSP) [Paulovich et al. 2008], a qual não se encaixa perfeitamente em nenhum grupo anteriormente citado. Diante disso, apenas estas serão abordadas com mais detalhes na subseção 3.2.1.

As técnicas de projeção citadas estão implementadas na ferramenta Projection Explorer (PEx) [Paulovich et al. 2007], desenvolvida no ICMC-USP. Tal ferramenta será apresentada na subseção 3.2.3 devido à sua utilização para a geração das projeções deste trabalho e pode ser encontrada para download em http://infoserver.lcad.icmc.usp.br/infovis2/PEx. Além das técnicas de projeção, a ferramenta $P E x$ inclui o cálculo da medida de silhueta, detalhada na subseção 3.2.2, a qual é usada para avaliar a qualidade das projeções de imagens obtidas.

A Figura 3.1 apresenta um exemplo de projeção do conjunto de dados IRIS usando a ferramenta PEx e a técnica LSP. Este conjunto consiste de uma coleção de 150 amostras, compostas de 4 atributos (comprimento da sépala, largura da sépala, comprimento da pétala e largura da pétala) correspondentes à 3 tipos de flores da família Iris (Iris Setosa, Iris Versicolour e Iris Virginica). Ressalta-se que uma classe é linearmente separável das outras duas, no entanto, as outras não são separáveis uma da outra. Tal conjunto pode ser obtido em http://archive.ics.uci.edu/ml/datasets/Iris.

\subsubsection{Técnicas de Projeção Utilizadas}

Existem inúmeras técnicas de projeção de dados. Dentre as diversas técnicas, aquelas pertencentes ao grupo Multidimensional Scaling - MDS buscam realizar um mapeamento injetivo dos dados originais nos dados projetados, preservando alguma relação de distância [Steyvers 2002]. Considerando $\delta\left(x_{i}, x_{j}\right)$ como a dissimilaridade entre dois objetos no espaço multidimensional e $d\left(f\left(x_{i}\right), f\left(x_{j}\right)\right)$ como a distância entre os pontos referentes a tais objetos, a $M D S$ busca aproximar $d\left(f\left(x_{i}\right), f\left(x_{j}\right)\right)$ de $\delta\left(x_{i}, x_{j}\right)$ para todo par de objetos. A forma como essa aproximação é realizada, permite a diferenciação de duas classes de $M D S$ [Cox and Cox 2000]: 

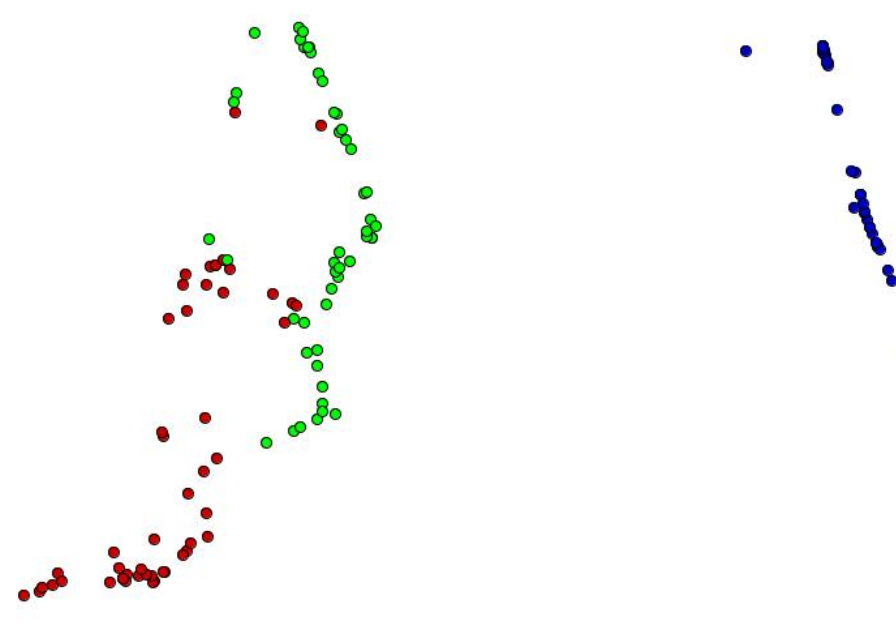

Figura 3.1: Exemplo de Projeção 2D do conjunto de dados IRIS. Cada cor indica uma classe diferente.

$M D S$ Métrico e $M D S$ não Métrico.

Técnicas de $M D S$ Métrico buscam aproximar a dissimilaridade entre os objetos multidimensionais com a distância entre os pontos no layout através de uma função de transformação linear $g$. Ou seja, busca-se que $\delta\left(x_{i}, x_{j}\right) \approx g\left(d\left(f\left(x_{i}\right), f\left(x_{j}\right)\right)\right)$ para todo par de objetos $x_{i}$ e $x_{j}$. Já no $M D S$ não Métrico busca-se estabelecer uma relação monotônica das distâncias entre os pontos com as dissimilaridades entre os objetos, através de uma função arbitrária $g$. Dessa forma, somente um rank (crescente ou decrescente) de dissimilaridades será preservado, ou seja, $\delta\left(x_{i}, x_{j}\right)<\delta\left(x_{k}, x_{n}\right) \Rightarrow g\left(\delta\left(x_{i}, x_{j}\right)\right)<g\left(\delta\left(x_{k}, x_{n}\right)\right)$, para todo $x_{i}, x_{j}, x_{k}, x_{n} \in X$ [Steyvers 2002].

Dentre as técnicas escolhidas para gerar as projeções deste trabalho, duas pertencem ao grupo $M D S$ métrico. São elas:

- Classical Scaling (CS): foi desenvolvida por Young [Young and Householder 1938] e classificada como uma técnica de $M D S$ por Torgerson [Torgerson 1952]. Tem como objetivo encontrar as coordenadas de um conjunto de pontos partindo-se de uma matriz composta pelas dissimilaridades dos objetos. Caso as dissimilaridades sejam distâncias euclidianas, a igualdade $\delta\left(x_{i}, x_{j}\right)=d\left(f\left(x_{i}\right), f\left(x_{j}\right)\right)$ pode ser satisfeita fazendo uma decomposição espectral da matriz [Young and Householder 1938]. Essa técnica apresenta resultados bastante satisfatórios quanto a sua precisão, mas, não é aplicável a conjuntos com mais de alguns milhares de objetos, pois possui complexidade computacional $O\left(n^{2}\right)$.

- Sammon's Mapping (SM): foi desenvolvida por Sammon [Sammon 1969] e é uma das técnicas mais conhecidas da área de visualização. Pertence ao conjunto de técnicas denominadas Least Squares Scaling (LSS). Estas técnicas buscam configurar os pontos fazendo com que $\delta\left(x_{i}, x_{j}\right) \approx g\left(d\left(f\left(x_{i}\right), f\left(x_{j}\right)\right)\right)$ através da minimização de uma função de 
perda. Variando a função de perda, obtêm-se diferentes resultados. Quando se trata da técnica Sammon's Mapping, a função de perda apresentada na equação 3.1 é minimizada. Ressalta-se que esta técnica possui complexidade $O\left(n^{2}\right)$.

$$
S=\frac{1}{\sum_{i<j} \delta\left(x_{i}, x_{j}\right)} \sum_{i<j} \frac{\left(d\left(y_{i}, y_{j}\right)-\delta\left(x_{i}, x_{j}\right)\right)^{2}}{\delta\left(x_{i}, x_{j}\right)}
$$

Além das técnicas Classical Scaling e Sammon's Mapping, a técnica Least Square Projection (LSP) [Paulovich et al. 2008] também foi utilizada para gerar algumas projeções. Esta é uma técnica de projeção para grandes conjuntos de dados multidimensionais que busca preservar relações de vizinhança (e não relações de distância) nos dados projetados. Dessa forma, a LSP tem como objetivo projetar na mesma vizinhança no plano, dados que são vizinhos no espaço multidimensional. Esta técnica possui dois passos principais: a definição dos pontos de controle e a construção de um sistema linear.

Primeiramente, um subconjunto dos objetos multidimensionais, chamado de pontos de controle, é escolhido e projetado utilizando alguma técnica de projeção que preserva as relações de distância precisamente. A escolha dos pontos de controle é muito importante, pois estes devem representar o mais fielmente possível a distribuição dos dados multidimensionais e possíveis grupos existentes. Diante disso, para escolhê-los executa-se um algoritmo de agrupamento nos dados obtendo grupos dos quais se selecionam os objetos mais representativos. Geralmente, os pontos de controle são os objetos mais próximos dos centróides.

Em seguida, constrói-se um sistema linear utilizando as relações de vizinhança dos objetos multidimensionais e as coordenadas cartesianas dos pontos de controle com o objetivo de projetar os objetos restantes de forma que os mesmos estejam localizados no fecho convexo dos seus $k$ vizinhos mais próximos, considerando uma vizinhança no espaço multidimensional. Detalhes da construção do sistema linear podem ser encontrados em [Paulovich 2008].

Uma característica importante da $L S P$ é sua capacidade de preservar tanto informação local (relações de vizinhança locais) quanto global entre os objetos (relações de similaridades e distâncias entre grupos de objetos multidimensionais). A informação global é preservada por meio do posicionamento dos pontos de controle e a informação local por meio da preservação da vizinhança dos objetos multidimensionais nos objetos projetados. No entanto, esta técnica tende a concentrar bem (sobrepor) os objetos de um determinado grupo, dificultando sua análise visual. Além disso, a $L S P$ é indicada para mais de 200 objetos por ser uma técnica de interpolação de uma pequena amostra do conjunto de dados, caso contrário pode-se utilizar uma técnica de Multidimensional Scaling sobre todos os objetos multidimensionais [Paulovich 2008]. 
Após projetar os dados usando as técnicas anteriormente citadas, é necessário comparar a qualidade das projeções geradas. Esta comparação pode ser feita qualitativamente, por meio da observação do usuário e, quantitativamente, por meio da medida de silhueta, a qual será apresentada a seguir.

\subsubsection{Medida de Silhueta}

A medida de silhueta [Kaufman and Rousseeuw 1990; Hruschka and Covões 2005] indica a qualidade de um agrupamento, ou seja, o grau de coesão dos dados pertencentes ao mesmo grupo e o grau de separação entre os diferentes grupos. Neste trabalho, a silhueta é utilizada para avaliar a qualidade das projeções. Seja $S=\left\{x_{1}, x_{2}, \ldots, x_{n}\right\}$ um conjunto de $n$ instâncias e, $k$ agrupamentos não sobrepostos representados por $C=\left\{C_{1}, C_{2}, \ldots, C_{k}\right\}$. Considerando a instância $x_{i}$ pertencente ao grupo $C_{j}$, a dissimilaridade média de $i$ para todas as outras instâncias de $C_{j}$ é dada por $a(i)$ (dissimilaridade intra-grupos).

Agora, considerando todos os grupos $C_{k}$, tal que $k \neq j$, a dissimilaridade média de $i$ para todas as outras instâncias dos grupos $C_{k}$ é dada por $d\left(i, C_{k}\right)$ (dissimilaridade extra-grupos). Depois de calcular $d\left(i, C_{k}\right)$ para todos os $C_{k}, k \neq j$, seleciona-se a menor delas, ou seja, $b(i)=\min d\left(i, C_{k}\right)$. Este valor representará a dissimilaridade de $i$ para o grupo vizinho. Por fim, a silhueta da instância $i$ é dada pela seguinte equação:

$$
s(i)=\frac{b(i)-a(i)}{\max \{a(i), b(i)\}}
$$

Quanto maior o valor obtido pela medida de silhueta $(-1 \leq s(i) \leq 1)$, melhor é a atribuição da instância $i$ a um dado agrupamento. Caso $s(i)=0$, não é possível saber se a instância $i$ deveria ter sido atribuída ao grupo atual ou ao grupo vizinho. A média de $s(i)$, para $i=$ $1,2, \ldots, n$, pode ser usada como um critério para avaliar a qualidade de uma dada partição. Fazendo isso, o melhor agrupamento é encontrado quando o valor da média é maximizado [Hruschka and Covões 2005].

A medida de silhueta é uma das técnicas implementadas na ferramenta Projection Explorer - PEx com o intuito de avaliar a qualidade das projeções obtidas. A seguir, apresenta-se a ferramenta $P E x$ devido à sua utilidade para o desenvolvimento deste trabalho. 


\subsubsection{Ferramentas PEx e PEx-Image}

Projection Explorer (PEx) é uma ferramenta desenvolvida no ICMC - USP, para geração e análise de projeções de dados multidimensionais [Paulovich et al. 2007]. Ela emprega técnicas de visualização e mineração de dados, e o resultado são projeções na forma de um conjunto de pontos em um plano. Os pontos podem ser coloridos ou terem seus tamanhos alterados com base em alguma informação extra mapeada sobre a projeção na forma de um campo escalar como, por exemplo, o mapeamento das classes dos objetos projetados.

Inicialmente, a ferramenta $P E x$ foi desenvolvida apenas para representar visualmente coleções de documentos. Nesta representação, cada documento é identificado por um ponto no plano de projeção. Se dois pontos estão próximos, o conteúdo dos documentos que eles representam são semelhantes, caso contrário, os documentos não são correlacionados ou são pouco correlacionados. Usando esta representação gráfica é possível identificar dentro de uma coleção de documentos, grupos semelhantes e as fronteiras entre os grupos de documentos, possibilitando verificar a correlação entre as diferentes áreas de conhecimento. Além disso, a PEx permite selecionar grupos de documentos, e criar para tais grupos etiquetas que identificam os temas principais por eles discutidos.

Entretanto, a potencialidade da ferramenta PEx pode extrapolar dados de coleções de texto e suas técnicas de projeção podem ser aplicadas a outros tipos de dados multidimensionais. Para isto, é necessário fornecer uma maneira de calcular a similaridade entre o conjunto dos dados após uma etapa de extração dos vetores de característica. Nesse contexto, surgiu a idéia da expansão da $P E x$ para a aplicação em conjuntos de imagens, dando origem a uma ferramenta chamada PEx-Image [Eler et al. 2008].

Na PEx-Image, cada imagem é representada por um ponto. Pontos próximos indicam imagens com características semelhantes e pontos distantes indicam imagens com características pouco relacionadas ou não relacionadas. A Figura 3.2 ilustra o resultado de uma projeção da PEx-Image para um conjunto de imagens, constituído por seis diferentes classes de imagens médicas, descrito por um vetor de 45 características. A Figura 3.2.(a) representa o mapeamento dos pontos por meio da técnica conhecida por Neighbor-Joining (NJ) com modelos em árvore filogenética [Cuadros et al. 2007]. A Figura 3.2.(b) mostra o mesmo mapeamento, porém os nós são substituídos pelos ícones de cada imagem, funcionalidade importante da PEx-Image.

A qualidade dos agrupamentos dos dados fornecida pelas técnicas de projeção inicialmente era aferida de forma subjetiva e dependia exclusivamente da aceitação do observador. Caso o observador julgasse insatisfatório o agrupamento, um novo subconjunto de características, dentre aqueles já computados, deveria ser selecionado. Alternativamente, uma nova técnica de projeção poderia ser aplicada, com o intuito de que um agrupamento melhor fosse obtido. Ne- 


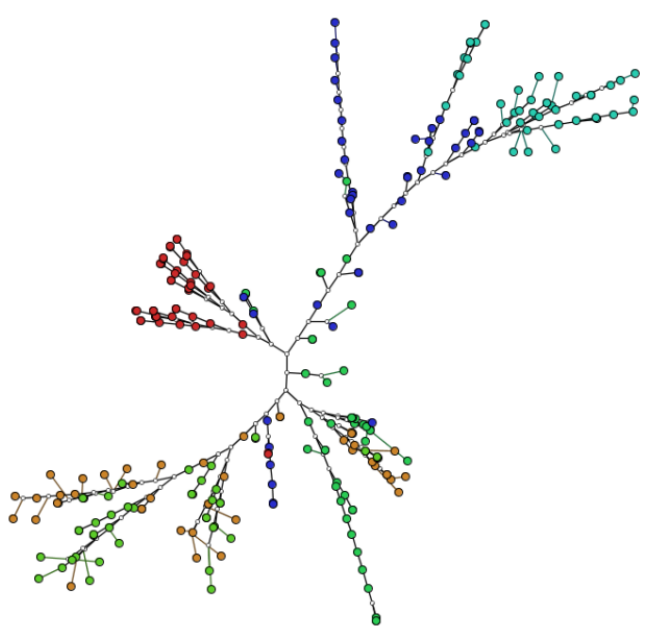

(a)

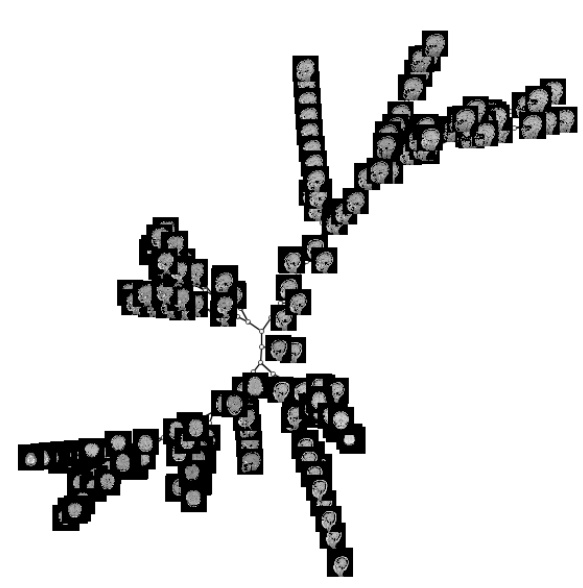

(b)

Figura 3.2: Projeção 2D de um conjunto de imagens médicas usando a técnica $N J$ com modelos em árvore filogenética.

nhuma medida quantitativa acerca do agrupamento era fornecida. No entanto, foi acrescentada à ferramenta PEx o cálculo da medida de silhueta (subseção 3.2.2) para averiguar a qualidade do agrupamento dos dados obtido pela técnica de projeção. Quanto maior o valor da silhueta, melhor o agrupamento e, consequentemente, melhor o subconjunto de características utilizado [Brandoli et al. 2010].

Além de avaliar a qualidade das projeções, as ferramentas PEx e PEx-Image também realizam, sobre o dado projetado, um processo automático de agrupamento por $K$-means. As Figuras 3.3.(a) e 3.3.(b) ilustram, respectivamente, um exemplo da projeção 3D e o agrupamento para um conjunto de 2800 artigos científicos, onde cada cor indica uma categoria de artigos. Esta funcionalidade da ferramenta é explorada no contexto deste trabalho de mestrado.

\subsection{Agrupamento}

Agrupamento (Clustering, em inglês) [Jain and Dubes 1988; Anderberg 1973] é uma técnica de classificação não supervisionada usada na identificação de alguma estrutura importante presente no conjunto de dados. O objetivo de analisar grupos é classificar dados em subconjuntos que tenham algum significado no contexto particular do problema. Espera-se que dados pertencentes a um determinado grupo sejam similares entre si, mas dissimilares à dados pertencentes a outros grupos. Os métodos de agrupamentos são muitos úteis na exploração de dados, ou 


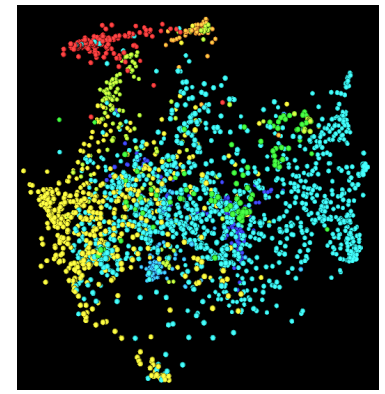

(a)

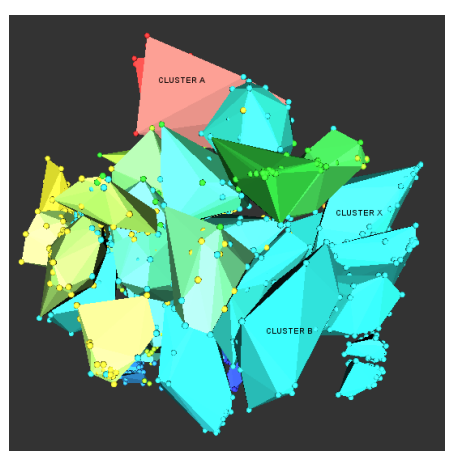

(b)

Figura 3.3: Projeção 3D de um conjunto de 2800 artigos científicos: a) projeção 3D onde cada vértice representa um artigo e cada cor, uma categoria de artigos; b) conjunto de agrupamentos representados por feixos convexos.

seja, caso existam grupos naturalmente presentes nos dados, pode-se nomeá-los e resumir suas propriedades, facilitando a sua interpretação [Webb 2002].

Considerando agrupamento baseado em centróides, pode-se definir formalmente agrupamento como o particionamento de $n$ objetos em um número $k$ de grupos, baseado em alguma métrica de similaridade/dissimilaridade, a qual determina a atribuição de um dado padrão para o domínio de um centróide de um grupo particular. Considerando $S=\left\{x_{1}, x_{1}, \ldots, x_{n}\right\}$ um conjunto de $n$ objetos e $k$ grupos representados por $C_{1}, C_{2}, \ldots, C_{k}$, as seguintes propriedades devem ser respeitadas pelos algoritmos de agrupamento:

1. $C_{i} \neq \varnothing$ para $i=1,2, \ldots, k$.

2. $C_{i} \cap C_{j}=\varnothing$ para $i=1,2, \ldots, k$ e $j=1,2, \ldots, k$ e $i \neq j$.

3. $\bigcup_{i=1}^{k} C_{i}=S$.

Existe um grande número de algoritmos de agrupamento, sendo que cada um é adequado para um tipo de aplicação. Um dos mais populares e utilizados é algoritmo K-means, proposto por Stewart Lloyd em 1957, mas, publicado somente em 1982 [Lloyd 1982]. Trata-se de um algoritmo que define o particionamento dos dados em termos de centróides, os quais geralmente consistem na média do agrupamento dos objetos [Tan et al. 2006]. Este algoritmo funciona da seguinte maneira. Primeiro, escolhe-se aleatoriamente $k$ centróides iniciais $z_{1}, z_{2}, \ldots, z_{k}$ dos $n$ objetos pertencentes a $S$. Em seguida atribui-se o objeto $x_{i}(i=1,2, \ldots, n)$ ao grupo $C_{j}$ $(j=1,2, \ldots, k)$ se:

$$
\left\|x_{i}-z_{j}\right\| \leq\left\|x_{i}-z_{p}\right\|
$$


Onde $p=1,2, \ldots, k$ e $j \neq p$, ou seja, atribui-se $x_{i}$ ao grupo cuja distância de $x_{i}$ ao centróide é menor. Após a atribuição dos objetos $x_{i}$ aos seus respectivos grupos, calculam-se novos centróides $z_{1}^{*}, z_{2}^{*}, \ldots, z_{k}^{*}$ da seguinte forma:

$$
z_{i}^{*}=\frac{1}{n_{i}} \sum_{x_{j} \in C_{i}} x_{j}
$$

Onde $i=1,2, \ldots, k$ e $n_{i}$ corresponde ao número de elementos do grupo $C_{i}$. Caso, $z_{i}^{*}=z_{i}$ para todos $i=1,2, \ldots, k$, o processo termina, caso contrário, recomeça a partir da atribuição dos objetos $x_{i}$ aos grupos.

Ressalta-se que o algoritmo $K$-means apresenta algumas desvantagens como, por exemplo, a solução é dependente dos centróides iniciais, pode-se convergir a ótimos locais e soluções globais de grandes problemas podem não ser encontradas em tempo razoável [Selim and Ismail 1984]. Diante disso, foi desenvolvido o algoritmo KGA-clustering [Bandyopadhyay and Maulik 2002] para tentar suprir as limitações do K-means.

\subsubsection{Algoritmo $K G A$-clustering}

O algoritmo KGA-clustering [Bandyopadhyay and Maulik 2002] introduz ao algoritmo Kmeans original a capacidade dos Algoritmos Genéticos (AGs) para prover perturbação no sistema, evitando ótimos locais. Este algoritmo determina $k$ centróides dos grupos no $\mathbb{R}^{N}$ através do agrupamento adequado de um conjunto de $n$ objetos não rotulados.

Considerando um espaço de características $N$-dimensional, cada cromossomo é representado por uma seqüência de $N * k$ objetos, onde as primeiras $N$ posições representam as $N$ dimensões do primeiro centróide do grupo e assim por diante. A soma das distâncias Euclidiana entre objetos e seus respectivos centróides é definida como métrica de clusterização $\mathbf{M}$ e o objetivo é buscar por centróides de agrupamentos onde $\mathbf{M}$ é minimizado. A cada geração, usam-se os princípios do K-means para determinar os novos centróides dos grupos e as características dos algoritmos genéticos (cruzamento, mutação) para gerar perturbações no sistema evitando valores ótimos locais. A seguir, são apresentados os passos principais do algoritmo KGA-clustering. Detalhes do algoritmo podem ser encontrados em [Bandyopadhyay and Maulik 2002].

1. Inicializa a população com $k$ objetos distintos escolhidos aleatoriamente do conjunto de dados.

2. $i=1$. 
3. Decodifica o i-ésimo cromossomo, encontra os centróides dos grupos $(z)$ e executa o agrupamento.

4. Calcula novos centróides $\left(z^{*}\right)$ para os grupos.

5. Substitui $z$ por $z^{*}$.

6. Calcula a métrica de clusterização e a aptidão.

7. $i=i+1$.

8. Verifica se $i<$ Tamanho da População. Caso seja verdade, volta para passo 3. Caso contrário, verifica se alcançou o critério de parada. Caso tenha alcançado, termina o processo, senão executa as operações genéticas (Seleção, Crossover e Mutação) e volta para o passo 2 .

Muitas vezes, nos problemas de agrupamento, o número de grupos $k$ não é conhecido a priori. Diante disso, deve-se encontrar o número de grupos antes de particionar os objetos. Para isso, existem várias técnicas como, por exemplo, a técnica desenvolvida por Hruschka [Hruschka and Covões 2005] baseada na medida de silhueta. Esta técnica foi utilizada em alguns experimentos realizados neste trabalho e por isso é explicada na seção seguinte.

\subsubsection{Encontrando o Número Correto de Agrupamentos}

O número de agrupamentos pode ser aproximado através da utilização das próprias medidas de avaliação de grupos. Por exemplo, ao se traçar um gráfico do número de grupos versus medida de avaliação, observam-se picos, curvas ou inclinações que podem estimar o número correto de agrupamentos. No entanto, nem sempre esta forma de aproximação gera o resultado correto [Tan et al. 2006].

Hruschka [Hruschka and Covões 2005] propôs uma forma de estimar o número de agrupamentos utilizando a versão simplificada [Hruschka et al. 2004] da medida de silhueta apresentada na subseção 3.2.2. Na silhueta simplificada, calcula-se a distância entre a instância $i$, $i=1,2, \ldots, n$ e os centróides dos grupos, e não mais a distância entre a instância $i$ e todos os elementos do grupo. Isto reduz a complexidade de $O\left(n^{2}\right)$ para $O(n)$.

Considerando o cálculo da silhueta simplificada e o algoritmo K-means, Hruschka encontra o número correto de agrupamentos $\left(k^{*}\right)$ através do seguinte algoritmo [Hruschka and Covões 2005]:

1. Escolhe-se o número mínimo e máximo de agrupamentos, $k_{\min }$ e $k_{\max }$ respectivamente, no conjunto de valores de $k$. Escolhe-se também a quantidade (representada por $p$ ) de partições iniciais. 
2. VSS $\leftarrow-1$, onde VSS corresponde ao valor da silhueta simplificada.

3. Para cada $k \in\left\{k_{\min }, \ldots, k_{\max }\right\}$ faça:

3.1. Gera aleatoriamente $p$ partições iniciais das instâncias em $k$ agrupamentos não vazios.

3.2. Executa o K-means para cada partição gerada e calcula sua silhueta simplificada. Armazena o melhor valor obtido em $M V O$.

3.3. Se $(M V O>V S S)$, então $V S S \leftarrow M V O$ e $k^{*} \leftarrow k$. Armazena a partição correspondente a $k^{*}$.

4. Retorna $V S S$ e sua partição correspondente a $k^{*}$.

Este algoritmo foi usado para encontrar o número de agrupamentos do conjunto de características, em alguns experimentos realizados neste trabalho.

\subsection{Considerações Finais}

Este capítulo apresentou técnicas importantes para o desenvolvimento deste trabalho de mestrado. Tais técnicas são utilizadas no desenvolvimento de uma nova abordagem de seleção de características. Primeiramente, as projeções de dados multidimensionais foram abordadas, destacando as técnicas Classical Scaling, Sammon's Mapping e Least Square Projection, visto que foram utilizadas neste trabalho de mestrado. Estas técnicas foram empregadas tanto em projeções de imagens quanto de características. Neste último caso, a projeção é usada como um processo de seleção com base na premissa de que grupos de características representam características correlacionadas, passíveis de serem descartadas. Todas as projeções de imagens obtidas são avaliadas quantitativamente por meio da medida de silhueta.

Em seguida, os algoritmos de agrupamento K-means e KGA-clustering foram descritos. Estes algoritmos são usados como seletores de características ao se considerar que os grupos obtidos apresentam características correlacionadas. Desta forma, apenas algumas amostras de cada grupo são selecionadas, configurando um processo de seleção. Além disso, estes algoritmos também são utilizados para gerar agrupamentos de características, os quais servirão como entrada para o seletor por saliência baseado em rede neural proposto (maiores detalhes no Capítulo 4).

Quando se trata de agrupamento de características, não se sabe a quantidade de grupos de características existentes. Diante disso, é necessário realizar um processo inicial para a obtenção do número de agrupamentos. Por isso, o algoritmo de Hruschka [Hruschka and Covões 2005] é 
apresentado. Ele gera uma estimativa do número adequado de grupos utilizando medida de silhueta e $K$-means. No próximo capítulo é apresentada a abordagem de seleção de características proposta, que explora as técnicas apresentadas, provendo um seletor eficiente. 


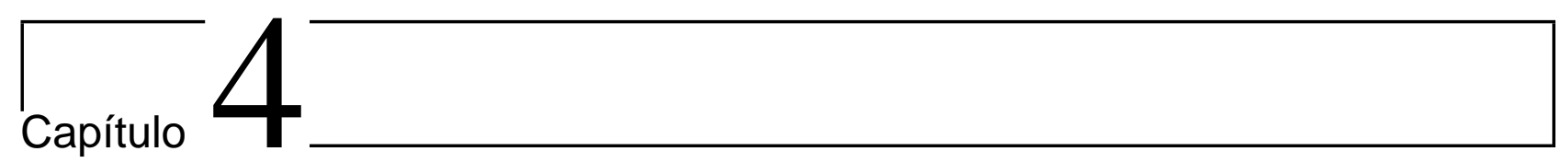

\section{Abordagem Proposta para a Seleção de Características}

\subsection{Considerações Iniciais}

Este capítulo apresenta a metodologia desenvolvida para a seleção de características apoiada por mineração visual de dados. Além disso, detalha-se o aprimoramento feito no seletor por saliência baseado em rede neural $M L P$. A seção 4.2 descreve como técnicas de projeção e agrupamentos, medida de silhueta e seletor baseado em saliência se inter-relacionam de forma a prover o seletor de características proposto. Já a seção 4.3 apresenta os conjuntos de imagens que foram utilizados nos experimentos, juntamente com as características extraídas de cada conjunto.

\subsection{Abordagem Proposta}

O diagrama ilustrado na Figura 4.1 apresenta a abordagem de seleção desenvolvida neste trabalho de mestrado.

Inicialmente, o conjunto original de dados é projetado. Representemos tal conjunto por uma matriz $M_{n \times m}$, composta por $n$ instâncias (imagens) com $m$ características cada. Em seguida, o conjunto original de dados é transposto, resultando em uma matriz $M_{m \times n}$, ou seja, com $m$ instâncias (características) e $n$ dimensões (imagens). A partir do conjunto transposto dois procedimentos podem ser realizados. O primeiro consiste em projetar as características. Tal projeção revela uma premissa importante introduzida no processo de seleção, onde cada amostra é uma característica e pontos próximos uns aos outros, sob o ponto de vista de reconhecimento 


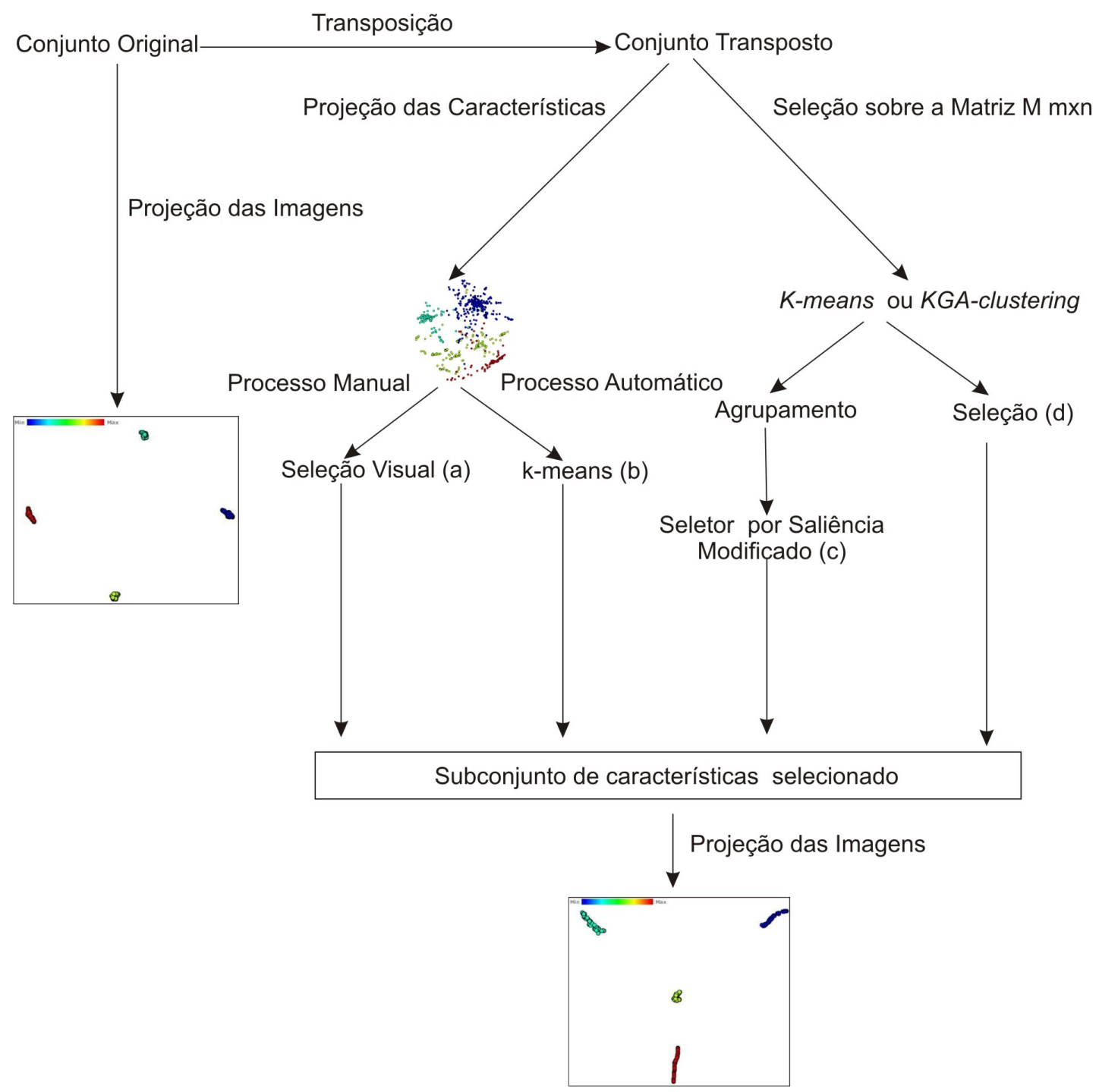

Figura 4.1: Diagrama referente à abordagem de seleção proposta neste trabalho.

de padrões, podem indicar características correlacionadas e que, juntas, não contribuem para aumentar o poder de discriminação (em muitos casos pioram a taxa de separabilidade de classes). Em contrapartida, amostras de agrupamentos distintos podem indicar características não correlacionadas, essenciais em um processo de classificação.

Com a projeção de características há dois cenários possíveis: (a) a revelação de agrupamentos bem definidos na projeção, a partir dos quais o usuário pode selecionar manualmente um subconjunto de características (uma ou mais amostras de cada agrupamento) e (b) a não revelação de agrupamentos facilmente perceptíveis na projeção. Diante disso, a seleção manual é substituída pela seleção automática, que é feita aplicando o algoritmo $K$-means sobre as características projetadas, tornando possível a obtenção de um subconjunto que sumarize o 
espaço de características. Ressalta-se que a seleção manual é guiada por um protocolo. Um ponto projetado sozinho sempre é selecionado, pois representa uma característica com alto poder discriminatório. No entanto, quando se trata da projeção de pontos totalmente sobrepostos, apenas uma amostra é selecionada, visto que tais pontos representam características correlacionadas, não contribuindo para aumentar o poder de discriminação.

O segundo procedimento consiste na aplicação de algoritmos de agrupamentos diretamente no conjunto transposto $M_{m \times n}$. Foram usados dois algoritmos, K-means e KGA-clustering. Este último supri algumas limitações do K-means como, por exemplo, a maior probabilidade de gerar ótimos locais, sendo teoricamente uma técnica mais apurada na identificação de agrupamentos mais consistentes e representativos, para dados de alta dimensionalidade.

Tais algoritmos foram utilizados com dois objetivos. O primeiro objetivo (c) consiste em usar a informação dos agrupamentos de características como entrada para o processo de seleção por saliência. Neste caso, consideram-se representantes dos agrupamentos de características e não mais o conjunto completo de características para efetuar o cálculo da saliência, diminuindo a quantidade de cálculos. Esta alteração proposta sobre o algoritmo de Santos [Santos and Batista Neto 2007] é descrita com mais detalhes na subseção 4.2.1. Por fim, o segundo objetivo da utilização dos algoritmos K-means e KGA-clustering consiste em gerar grupos de características, a partir dos quais seleciona-se um subconjunto de características (uma ou mais amostras de cada grupo), geralmente as mais próximas do centróide de cada agrupamento, configurando um processo de seleção (Seleção(d)).

Os subconjuntos de características selecionados pelos quatro processos (a, b, c, d) são, então, utilizados para gerar novas projeções de imagens. Estas projeções são comparadas tanto subjetivamente, por meio da análise visual de um observador, como quantitativamente, por meio da medida de silhueta. Esta comparação também se dá com relação à projeção obtida com o conjunto original de características, em que não ocorreu o processo de seleção. Com isso, verifica-se a qualidade dos subconjuntos selecionados.

Uma outra forma de avaliação dos subconjuntos de características obtidos nos processos de seleção é por meio da classificação. Para isso, foi utilizada uma rede neural $M L P$ como classificador e verificou-se a taxa de erro de classificação da rede considerando o conjunto completo de características e os subconjuntos selecionados. Detalhes do procedimento de treinamento e teste da rede neural usada para a classificação são apresentados na subseção 4.2.2.

\subsubsection{Seletor por Saliência Proposto}

Partindo da premissa de que amostras de um único agrupamento são características correlacionadas podemos compor um seletor por saliência, baseado em rede neural $M L P$, com uma 
configuração diferente. Com isso, o cálculo da saliência passa a considerar grupos de características e não mais o conjunto completo de características. Para isso, as características são previamente particionadas por meio de um algoritmo de agrupamento. A Figura 4.2 ilustra a nova configuração do seletor por saliência proposto.

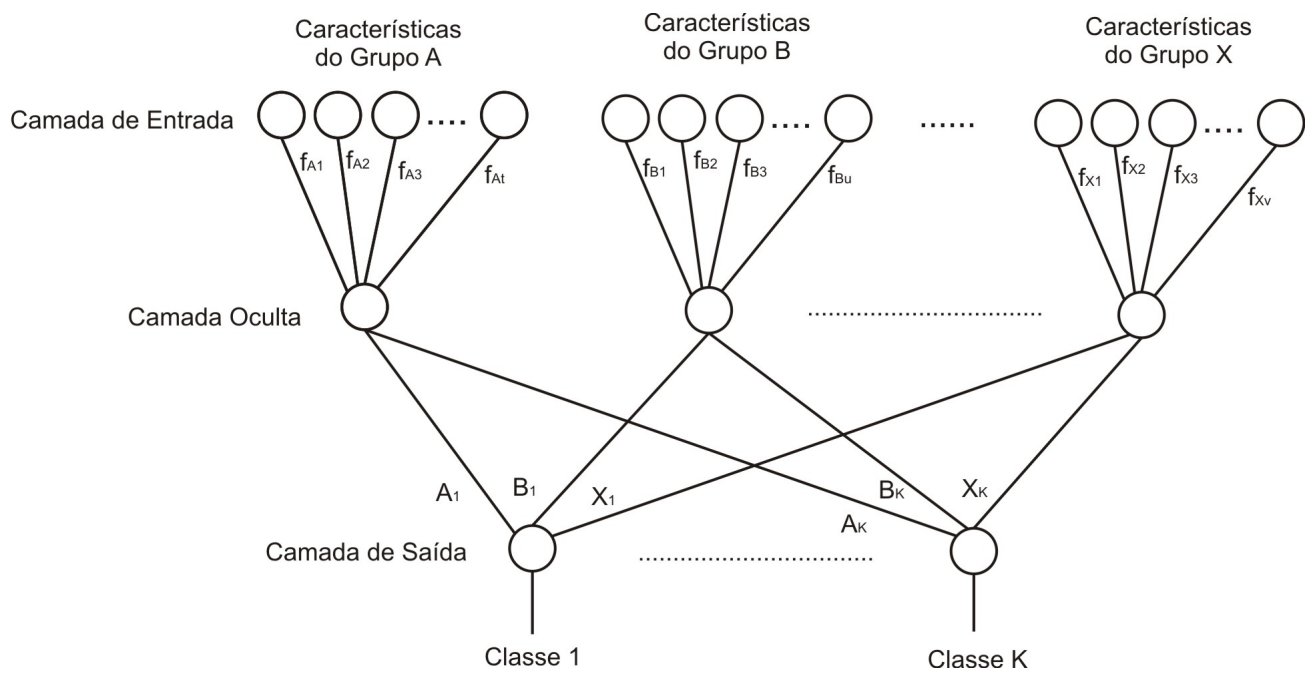

Figura 4.2: Nova configuração do seletor por saliência baseado em $M L P$ com informações provenientes de grupos de características.

Observando a Figura 4.2 percebe-se que as características são particionadas em vários grupos $(A, B, \ldots, X)$, os quais podem possuir um número diferente de elementos. Características pertencentes a um mesmo grupo são ligadas a um único neurônio da camada oculta. Ressaltase que o seletor tradicional, conforme apresentado no Capítulo 2, possui complexidade $O\left(\mathrm{~m}^{2}\right)$ ( $m$ é o número de características), no entanto, nesta nova configuração o número de neurônios na camada oculta cai drasticamente, visto que passa a ser igual ao número de grupos obtidos, sendo desprezível no cálculo da complexidade para altos valores de $m$, tornando o processo de obtenção das saliências mais rápido.

O processo de seleção é capaz de gerar, para cada agrupamento, um ranking de saliências para cada característica, além de uma medida de saliência para cada grupo. A seleção das características mais aptas consiste na manutenção daquela de maior valor de saliência para cada agrupamento. Adicionalmente, grupos de características com baixo valor de saliência podem ser excluídos, uma vez que isto indica um conjunto com baixo valor discriminante.

Formalmente, o novo cálculo da saliência é feito da seguinte forma: considerando $S=$ $\left\{x_{1}, x_{2}, \ldots, x_{m}\right\}$ um conjunto de $m$ características previamente agrupadas em $k$ agrupamentos não sobrepostos representados por $C=\left\{C_{1}, C_{2}, \ldots, C_{k}\right\}$, calcula-se um fator de normalização $N_{k}$, para cada neurônio $k$ oculto (lembrando que quantidade de neurônios é igual ao número de 
grupos). Este fator consiste na soma do módulo de suas conexões $w_{e, k}^{\text {camadaOculta }}$ (onde o índice e corresponde ao número do nó de entrada), de acordo com as características pertencentes a cada grupo:

$$
N_{k}=\sum_{e \in C_{k}} \mid w_{e, k}^{\text {camadaOculta } \mid}
$$

Cada combinação de caminhos possíveis (acrescentando-se à notação a variável $s$ para neurônios de saída) retorna um determinado valor $w_{e_{\in C_{k}}^{*}, k, s}$, para cada $k$, baseado no peso normalizado da entrada e no valor do peso de saída:

$$
w_{e_{\in C_{k}}, k, s}^{*}=\frac{\left|w_{e \in C_{k}, k}^{\text {camadaOculta }}\right|\left|w_{k, s}^{\text {camadaDeSaida }}\right|}{N_{k}}
$$

Assim, a medida de saliência $S_{e_{\in C_{k}}, s}$ da entrada $e$ para a saída $s$ é dada pela equação 4.3 .

$$
S_{e_{\in C_{k}}, s}=\sum_{k} w_{e_{\in C_{k}}, k, s}^{*}
$$

E a saliência média de cada um dos $k$ agrupamentos $S_{C_{k}}$ é dada por:

$$
S_{C_{k}}=\frac{\sum S_{e \in C_{k}}, s}{M_{k}}
$$

Onde $M_{k}$ corresponde a quantidade de características pertencentes ao agrupamento $k$. Caso sejam consideradas diversas saídas, a saliência total STe da entrada e pode ser calculada pela equação 4.5, conforme proposto em [Santos and Batista Neto 2007]:

$$
S T e=\sum_{s} \frac{S_{e_{\in C_{k}}, s}}{\sum_{f} S_{f, s}}
$$

Como dito anteriormente, o seletor por saliência é baseado em uma rede neural MLP. Tal rede deve ser inicialmente treinada para obter os pesos e permitir a seleção de características. Além disso, esta rede neural também foi usada como um classificador, com o intuito de obter o erro de classificação, considerando o conjunto completo de característica e os subconjuntos selecionados. A seguir, são apresentadas as estratégias de treino e teste da rede neural usada para obter as taxas de classificação das imagens.

\subsubsection{Estratégias de Treino e Teste da Rede Neural}

Uma rede neural $M L P$ foi utilizada como classificador do conjunto de imagens com o intuito de verificar quantitativamente a qualidade dos subconjuntos de características selecionados. 
Para validar os resultados obtidos pela rede neural, alguns procedimentos para a realização do treinamento e teste da rede foram adotados, a começar pela técnica de validação escolhida:

- Stratified K-fold-cross-validation: o conjunto de imagens original é dividido aleatoriamente em $K$ partições, sem repetição de elementos. Das $K$ partições, uma é mantida para validar (testar) a rede e as $K-1$ partições remanescentes são usadas para treinar a rede. O processo de validação cruzada é repetido $K$ vezes, com cada uma das $K$ partições sendo usadas exatamente uma vez como dados de validação. Ao final, pode-se calcular uma média dos $K$ resultados para produzir uma estimativa única. Ressalta-se que as partições selecionadas devem conter aproximadamente a mesma proporção de amostras de cada classe. A vantagem deste método é que todas as amostras são usadas para treinamento e validação da rede e cada amostra é usada para validação exatamente uma vez.

Ressalta-se que em cada uma das $K$ validações, a partição de validação foi usada para realizar dois treinamentos da rede neural. Como nem sempre a rede neural chega à mesma resposta para o conjunto de entrada, esse procedimento foi realizado apenas para confirmar os resultados.

\subsection{Conjuntos de Imagens e Extratores de Características Utilizados}

Os experimentos foram realizados sobre dois conjuntos de imagens: Rotate $^{1}$ e Scene $^{2}$. O conjunto Rotate contém 12 classes de imagens de texturas, onde cada imagem está digitalizada em um ângulo de rotação diferente $\left(0^{\circ}, 30^{\circ}, 60^{\circ}, 90^{\circ}, 120^{\circ}, 150^{\circ}\right.$ e $\left.200^{\circ}\right)$, resultando em um conjunto com 84 imagens. A Figura 4.3 apresenta uma imagem de cada classe, para o ângulo igual a $0^{\circ}$.

No entanto, para a realização dos experimentos, selecionamos apenas a imagem wood em quatro ângulos de rotação diferentes $\left(0^{\circ}, 30^{\circ}, 60^{\circ}\right.$ e $\left.90^{\circ}\right)$, conforme apresentado na Figura 4.4, permitindo a "fabricação" de testes parcialmente supervisionados. Logo tem-se 4 classes de imagens, com uma quantidade de imagens variável, visto que as imagens são subdividas compondo o conjunto do tamanho desejado.

O conjunto Scene é composto por paisagens naturais. Este possui 13 classes distintas, com variado número de imagens. No entanto, este trabalho utilizou apenas 3 classes (construções,

\footnotetext{
${ }^{1} \mathrm{http}: / /$ sipi.usc.edu/database/database.cgi?volume=rotate

${ }^{2}$ http://vision.cs.princeton.edu/Databsets/SceneClass13.rar
} 


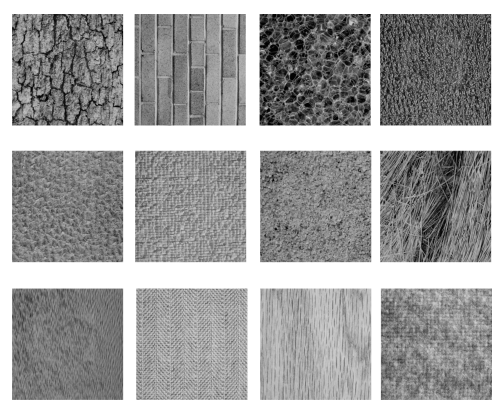

Figura 4.3: Conjunto de Imagens Rotate: Uma amostra de cada classe, considerando o ângulo de rotação $0^{\circ}$.

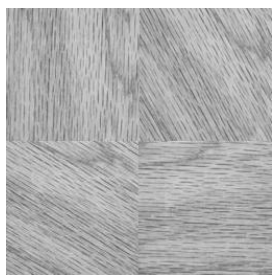

Figura 4.4: Mosaico de textura de madeira com quatro classes: $0^{\circ}$ (acima esq.), $30^{\circ}$ (acima dir.), $60^{\circ}$ (abaixo esq.) e $90^{\circ}$ (abaixo dir.).

costas oceânicas e florestas) e a quantidade de imagem variou de acordo com o experimento realizado. A Figura 4.5 apresenta exemplos de imagens apenas das 3 classes utilizadas neste trabalho.

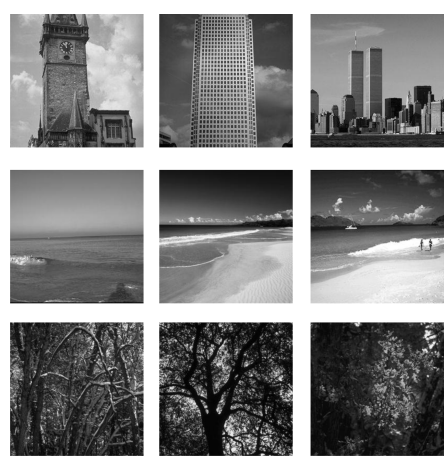

Figura 4.5: Conjunto de Imagens Scene: exemplos de amostras das classes construções, costas oceânicas e florestas.

Após a escolha dos conjuntos de imagens utilizados nos experimentos é necessário definir as técnicas responsáveis pela extração das características das imagens. Optamos por Filtros de Gabor [Gabor 1946] e Características de Tamura [Tamura et al. 1978]. Ambas são utilizadas para analisar textura. Os Filtros de Gabor permitem a variação do número de características obtido, conforme modificam-se os parâmetros escala $s=1, \ldots, S$ e orientação 
$o=1, \ldots, O$. Ao variar tais parâmetros, alguns aspectos da textura são realçados. Além disso, pode-se escolher qual medida (média, variância e/ou energia) usar para representar as imagens filtradas. Neste trabalho, várias combinações de parâmetros foram utilizadas para gerar as características por meio dos Filtros de Gabor. Já as Características de Tamura descrevem 6 atributos de textura: coarseness, contrast, directionality, linelikeness, regularity e roughness.

\subsection{Considerações Finais}

Este capítulo apresentou uma nova abordagem de seleção de características baseada em projeção de dados multidimensionais. Além disso, o seletor por saliência baseado em rede neural $M L P$, proposto por Santos [Santos and Batista Neto 2007], foi aprimorado, passando a considerar agrupamentos de características no cálculo da saliência e não mais o conjunto completo, o que diminui a quantidade de cálculos para a obtenção da saliência. Devido à falta de um protocolo padrão para comparar os resultados alcançados pela abordagem proposta, considerou a seleção de características por meio dos algoritmos de agrupamento $K$-means e KGA-clustering.

Os subconjuntos obtidos são usados no cálculo de novas projeções de imagens, as quais são avaliadas qualitativamente, por um observador, e quantitativamente, pela medida de silhueta. Além disso, um classificador baseado em rede neural $M L P$ foi utilizado para avaliar os subconjuntos selecionados por meio da taxa de erro de classificação. Os resultados da abordagem de seleção proposta são apresentados no próximo capítulo. 


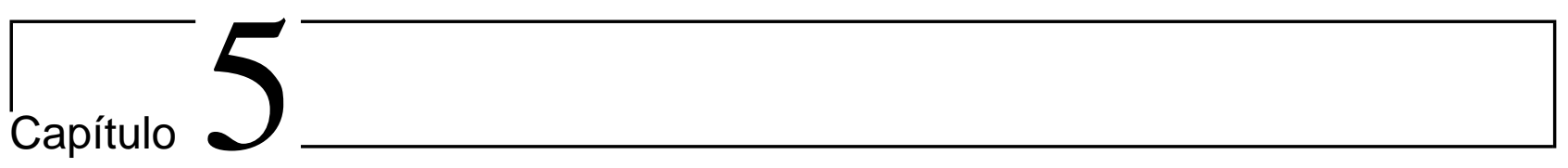

\section{Resultados}

\subsection{Considerações Iniciais}

Este capítulo descreve 4 experimentos, cada qual ilustrando aspectos distintos, conforme apresentado no diagrama 4.1 do capítulo 4, da metodologia proposta. O primeiro experimento ilustra a seleção visual de características, aborda a maldição da dimensionalidade como consequência da transposição do conjunto de dados e faz uma comparação com a seleção de características por meio do algoritmo K-means. O segundo experimento introduz o seletor por saliência proposto neste trabalho, comparando-o com o seletor por saliência proposto por Santos [Santos and Batista Neto 2007]. O terceiro experimento trata da determinação do número adequado de agrupamentos de características, informação usada pelo seletor por saliência proposto. Por fim, o quarto experimento aborda a influência de diferentes técnicas de projeção na seleção visual de características e ainda faz uma comparação com a seleção aleatória de características.

\subsection{Experimento 1}

O primeiro experimento teve como objetivo apresentar a seleção de características apoiada por projeção e comparar com a seleção por meio do algoritmo K-means. Além disso, avaliou-se a tranposição do conjunto de dados original, a qual pode levar à maldição da dimensionalidade. Este experimento foi subdivido em duas etapas. A primeira emprega o banco de imagens Rotate e investiga até que ponto a tranposição do conjunto de dados pode potencializar a maldição da dimensionalidade, uma vez que a relação entre o número de instâncias e o número de observações é severamente alterada. A segunda etapa utiliza o banco de imagens Scene e 
aborda a seleção manual de características. Em ambas as etapas, os resultados obtidos pela seleção apoiada por projeção foram comparados com a seleção por meio do algoritmo K-means aplicado diretamente sobre o conjunto de dados transposto.

Etapa 1: Esta etapa usou a técnica de projeção Least Square Projection e amostras (imagens) provenientes da imagem wood, do Banco Rotate, em quatro ângulos de rotações diferentes $\left(0^{\circ}, 30^{\circ}, 60^{\circ}\right.$ e $\left.90^{\circ}\right)$. As características foram extraídas utilizando os Filtros de Gabor, para 4 escalas, 20 orientações e 3 medidas (média, variância e energia), totalizando 240 características. Dois testes foram conduzidos: o primeiro, com 240 imagens (60 por classe), e o segundo com 784 imagens (196 por classe). O objetivo em se variar a quantidade de amostras é avaliar o método em uma situação típica de ocorrência da maldição da dimensionalidade. Para o conjunto de 784 amostras e 240 características, ao transpor o conjunto de dados, teremos 240 amostras e um total de 784 dimensões, configurando a situação. As amostras no conjunto de dados original são pré-rotuladas e cada uma das 4 classes é representada na projeção por uma cor distinta.

A Figura 5.1(a) ilustra uma projeção do conjunto com 240 imagens para todas as 240 características. Percebe-se que as 4 classes $\left(0^{\circ}\right.$ - azul, $30^{\circ}$ - verde, $60^{\circ}$ - amarelo e $90^{\circ}$ - vermelho $)$ foram perfeitamente separadas na projeção, evidenciando que os Filtros de Gabor são bons discriminantes para este caso. Em seguida, o conjunto original de dados é transposto e projetado. Entretanto, a projeção não revela agrupamentos perfeitamente delineados, conforme pode ser observado na Figura 5.1(b). Assim, ao invés de se aplicar a seleção manual, é empregado o algoritmo $K$-means sobre os dados projetados, considerando aleatoriamente a existência de 4 grupos de características. A projeção dos dados transpostos com os 4 agrupamentos computados por K-means pode ser vista na Figura 5.1(b), onde cada cor representa um grupo distinto. Para cada um dos 4 agrupamentos, 3 amostras de cada grupo foram tomadas, totalizando 12 características. Ressalta-se que foram consideradas as 3 amostras mais próximas do centróide de cada grupo.

Para avaliar o resultado da seleção por meio de projeções, aplicou-se o algoritmo K-means diretamente sobre o conjunto transposto $M_{m \times n}$. Para fins de comparação, foram também considerados 4 agrupamentos e tomadas 3 amostras de cada agrupamento (as mais próximas do centróide de cada agrupamento). As Figuras 5.2(a) e (b) ilustram as projeções das 240 imagens considerando os subconjuntos selecionados pelo K-means aplicado sobre a projeção e pelo $K$-means aplicado diretamente sobre o conjunto transposto, respectivamente. As medidas de silhueta obtidas nas projeções são apresentadas na Tabela 5.1. Os valores entre parênteses na tabela indicam a quantidade de características empregadas em cada projeção.

O segundo teste empregou as mesmas características e procedimentos do teste anterior, 


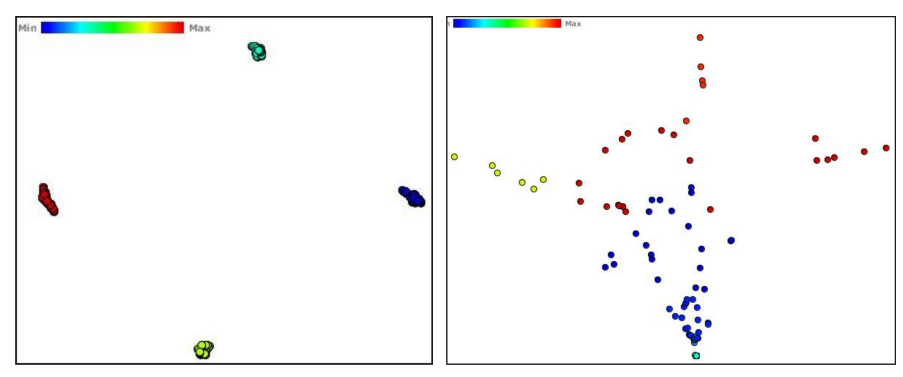

(a)

(b)

Figura 5.1: Projeção das 240 amostras. (a) Projeção do conjunto original de dados. (b) Projeção dos dados transpostos com os quatro agrupamentos computados por $K$-means (cada ponto indica uma característica).

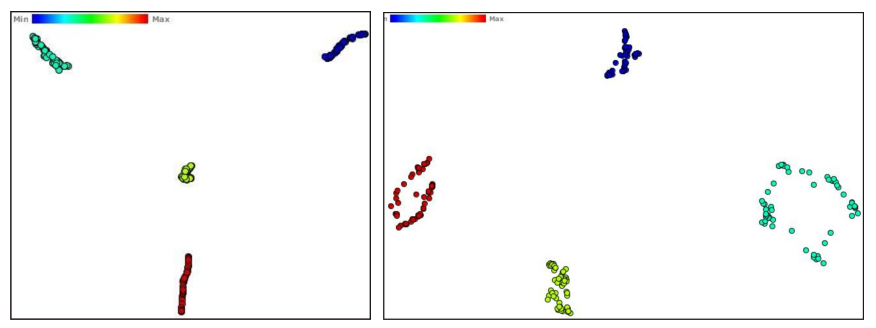

(a)

(b)

Figura 5.2: Projeção das 240 imagens. (a) Subconjunto de características selecionado pela aplicação do K-means sobre os dados projetados. (b) Subconjunto de características selecionado pela aplicação do K-means diretamente no conjunto transposto.

Tabela 5.1: Medidas de silhueta obtidas das projeções para o conjunto de 240 imagens do banco Rotate.

\begin{tabular}{c|c}
\hline Método de Seleção & Silhueta \\
\hline \hline Sem seleção (240) & 0,9693 \\
Seleção baseada em projeção (12) & 0,8952 \\
Seleção por meio do K-means (12) & 0,8472 \\
\hline
\end{tabular}

variando apenas a quantidade de imagens, que foi igual a 784. As projeções de imagens considerando os subconjuntos selecionados apresentaram qualidade visual satisfatória, visto que as quatro classes foram adequadamente separadas na projeção, mesmo utilizando apenas $5 \%$ das características. No entanto, tais projeções não foram mostradas devido à semelhança com as projeções anteriores. Já os valores de silhueta obtidos são apresentados na Tabela 5.2.

Em ambos os testes, ao observar as projeções das imagens após a seleção de características percebe-se que as quatro classes distintas são apresentadas separadamente, ou seja, a qualidade visual das projeções se mantém após a seleção, conforme pode ser observado na Figura 
Tabela 5.2: Medidas de silhueta obtidas das projeções para o conjunto de 748 imagens do banco Rotate

\begin{tabular}{c|c}
\hline Método de Seleção & Silhueta \\
\hline \hline Sem seleção (240) & 0,9235 \\
Seleção baseada em projeção (12) & 0,8312 \\
Seleção por meio do K-means (12) & 0,7661 \\
\hline
\end{tabular}

5.2(a), ressaltando que 95\% das características foram eliminadas. Em relação ao algoritmo K-means, percebe-se que este obtém subconjuntos de características com representatividade inferior àqueles obtidos pela projeção de características.

Ao se comparar os resultados dos dois testes com o intuito de avaliar a influência da maldição da dimensionalidade quando se transpõe o conjunto de dados, observa-se que o valor das silhuetas obtidas nas projeções do segundo teste diminuiu em torno de $6 \%$, demonstrando que a maldição da dimensionalidade exerce alguma influência nos resultados obtidos. No entanto, não chega a causar prejuízos na distinção das classes nas projeções, pois a qualidade visual se mantém.

Etapa 2: Esta etapa foi realizada usando a técnica de projeção Least Square Projection e o Banco Scene, composto por 200 imagens, sendo 100 imagens de construções e 100 de costas oceânicas. As características foram extraídas por meio dos Filtros de Gabor, para 4 escalas, 12 orientações e apenas a função média, totalizando 48 características.

A Figura 5.3(a) ilustra a projeção do conjunto original de dados com 200 imagens para todas as características, onde pontos azuis representam imagens de construções e pontos vermelhos representam imagens de costas oceânicas. Em seguida, foi realizado o processo de seleção: o conjunto de dados foi transposto e projetado, revelando sete agrupamentos, conforme ilustra a Figura 5.3(b). O usuário, então, selecionou aleatoriamente uma amostra de cada agrupamento, compondo um subconjunto com 7 características. Para fins de comparação, aplicou-se o algoritmo K-means sobre o conjunto transposto não projetado, para 7 agrupamentos, tomando uma única amostra de cada agrupamento (a mais próxima do centróide). A Figura 5.4 ilustra as projeções das 200 imagens para o subconjunto gerado pela seleção visual e o obtido pelo método de seleção por K-means. As medidas de silhueta obtidas nas projeções são apresentadas na Tabela 5.3.

Observando os valores de silhueta obtidos nas projeções percebe-se que ocorre uma pequena variação, ressaltando que houve um aumento no valor da silhueta obtido na projeção que utiliza apenas cerca de $15 \%$ das características selecionadas por meio visual. Além disso, a qualidade 


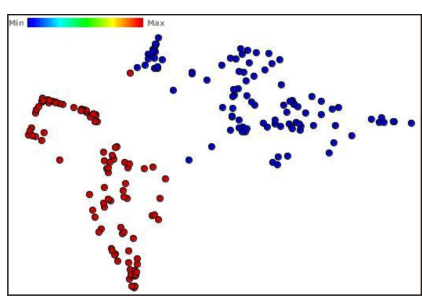

(a)

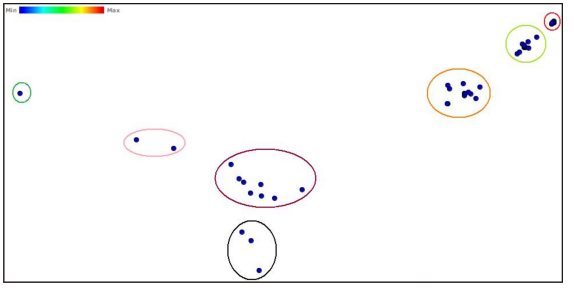

(b)

Figura 5.3: Projeção das 200 amostras. (a) Projeção do conjunto original de dados. (b) Projeção dos dados transpostos (cada ponto representa uma característica).

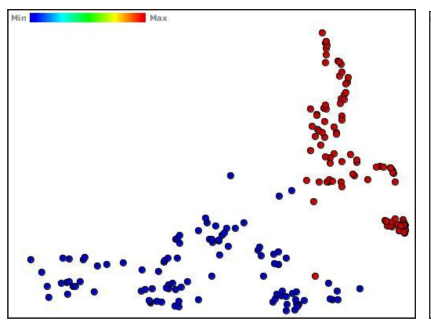

(a)

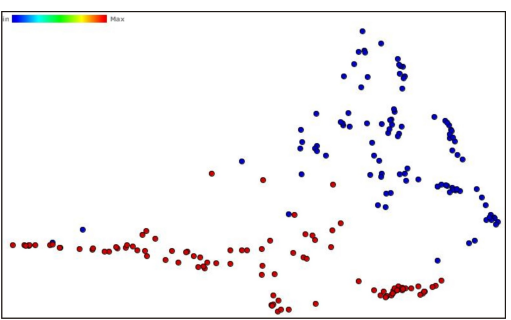

(b)

Figura 5.4: Projeções das 200 imagens. (a) Subconjunto de características selecionado visualmente. (b) Subconjunto de características selecionado pela aplicação do K-means diretamente no conjunto transposto.

Tabela 5.3: Medidas de silhueta obtidas das projeções para o conjunto de 200 imagens do banco Scene.

\begin{tabular}{c|c}
\hline Método de Seleção & Silhueta \\
\hline \hline Sem seleção (48) & 0,5353 \\
Seleção baseada em projeção (7) & 0,5373 \\
Seleção por meio do K-means (7) & 0,4031 \\
\hline
\end{tabular}

visual das projeções obtidas se mantém, pois as imagens de classes diferentes permanecem separadas após a seleção.

\section{$5.3 \quad$ Experimento 2}

O segundo experimento tem por objetivo introduzir a seleção de características por meio do seletor por saliência baseado em rede neural $M L P$, proposto neste trabalho. Este estudo empregou 784 imagens (196 por classe) provenientes da imagem wood, do Banco Rotate, em quatro ângulos de rotação diferentes $\left(0^{\circ}, 30^{\circ}, 60^{\circ}\right.$ e $\left.90^{\circ}\right)$. As características foram extraídas 
usando os Filtros de Gabor para 4 escalas, 12 orientações e a função média, resultando em 48 características.

Para a realização do treinamento da rede neural dividimos o conjunto de imagens em treino (588 imagens, sendo 147 por classe) e teste (196, sendo 47 por classe) e usamos o método Stratified $K$-fold-cross-validation, para $K=4$, para validar os resultados. Ressalta-se que cada partição foi usada para realizar 2 treinamentos da rede e uma média foi obtida. O agrupamento das características foi feito pelo algoritmo $K G A$-clustering, considerando o número de grupos igual a 6. Diante disso, o número de neurônios da camada oculta também é 6 .

Do seletor por saliência proposto, foi selecionado um subconjunto com as 10 características mais significativas. Para fins de comparação, também foi utilizado o Seletor por Saliência (SS) proposto por Santos [Santos and Batista Neto 2007], para a seleção de um subconjunto com as 10 melhores características. A Tabela 5.4 apresenta a média geral da taxa de erro de classificação dos conjuntos de teste, considerando os subconjuntos selecionados pelos dois seletores por saliência e o conjunto completo de características. Os valores entre parênteses representam a quantidade de características utilizadas.

Tabela 5.4: Média da taxa de erro de classificação considerando os subconjuntos selecionados pelos seletores por saliência e o conjunto completo de características.

\begin{tabular}{c|c}
\hline Método de Seleção & Taxa de Erro de Classificação \\
\hline \hline Seletor Santos (10) & $0 \%$ \\
Seletor Proposto (10) & $0 \%$ \\
Sem Seleção (48) & $54,97 \%$ \\
\hline
\end{tabular}

Os subconjuntos obtidos pelos seletores de características também foram usados para gerar novas projeções para conjunto total de imagens. Tais projeções foram geradas por meio das técnicas Sammon's Mapping (SM), Classical Scaling (CS) e Least Square Projection (LSP). A Tabela 5.5 apresenta as medidas de silhueta obtidas considerando o conjunto completo de características e os subconjuntos selecionados.

Tabela 5.5: Média das silhuetas obtidas para o conjunto de 784 imagens do banco Rotate, considerando diferentes técnicas de projeção.

\begin{tabular}{c|c|c|c}
\hline Método de Seleção & $S M$ & $C S$ & $L S P$ \\
\hline \hline Seletor Santos (10) & 0,63 & 0,65 & 0,68 \\
Seletor Proposto (10) & 0,73 & 0,78 & 0,81 \\
Sem Seleção (48) & 0,76 & 0,86 & 0,87 \\
\hline
\end{tabular}


Ao observar as taxas de erro de classificação obtidas pelas rede neural $M L P$ percebe-se a importância da seleção de características. Quando se utiliza os subconjuntos selecionados (cerca de $21 \%$ do total das características) por ambos os seletores por saliência tem-se $100 \%$ de acerto de classificação. Deve-se salientar que o excelente resultado de classificação obtido com os subconjuntos selecionados deve-se também à simplicidade do conjunto de imagens.

Ao se comparar as medidas de silhueta obtidas das projeções das imagens considerando os subconjuntos selecionados por ambos os seletores por saliência, nota-se que o seletor por saliência proposto neste trabalho apresenta valores de silhueta maiores que o seletor proposto por Santos. Este resultado é percebido visualmente nas projeções, conforme pode ser observado nas Figuras 5.5, 5.6 e 5.7. No entanto, após a seleção o valor da medida de silhueta obtida das projeções é levemente menor que àqueles das projeções considerando todas as características, mas, percebe-se que a qualidade visual das projeções é mantida, isto é, as classes continuam perfeitamente separáveis visualmente nas projeções que utilizam os subconjuntos selecionados, principalmente pelo seletor por saliência proposto. Em relação às diferentes técnicas de projeção, a $L S P$ gera grupos de imagens mais coesos.

Um resultado importante que deve ser considerado é o contraste obtido em relação a taxa de acerto de classificação e valores de silhueta. Esperava-se que, após a seleção, a taxa de classificação aumentasse e, consequentemente, o valor de silhueta também, mas, constatou-se que nem sempre isso acontece. Observando as Tabelas 5.4 e 5.5 nota-se que após a seleção de características a taxa de classificação aumenta consideravelmente, passando de $45.03 \%$ para 100\%, no entanto, o valor da silhueta após a seleção diminui levemente. Acredita-se que este resultado pode ser causado por alguma configuração da rede neural, o que pode ter gerado problemas como, por exemplo, o overfitting da rede (a rede memoriza os dados de treinamento ao invés de extrair as informações que permitirão a generalização), não permitindo a seleção de subconjuntos mais representativos. Porém, esta é uma questão a ser tratada em trabalhos futuros.

Uma outra questão que não foi tratada neste experimento é a obtenção do número correto de agrupamentos de características. Isso é importante pois o seletor por saliência proposto utiliza como entrada o conjunto de características agrupado em um determinado número de grupos, o qual também define a quantidade de neurônios da camada oculta da rede neural. Esta questão é tratada no próximo experimento. 


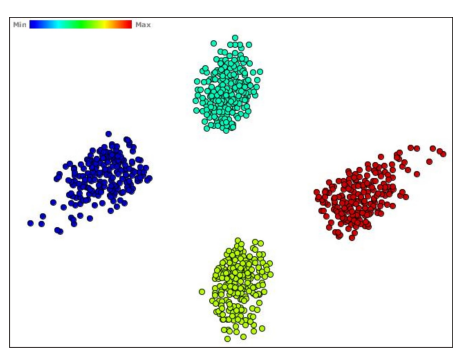

(a)

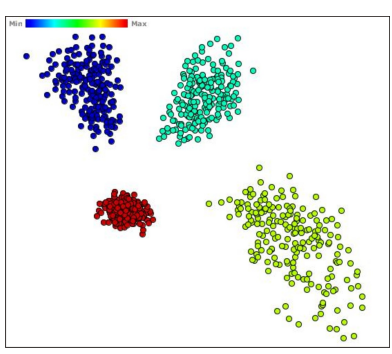

(b)

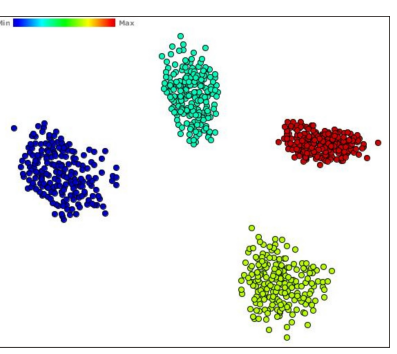

(c)

Figura 5.5: Técnica de Projeção Sammon's Mapping. (a) Projeção do conjunto original de dados. (b) Subconjunto de características selecionado pelo seletor proposto por Santos. (c) Subconjunto de características selecionado pelo seletor proposto neste trabalho.

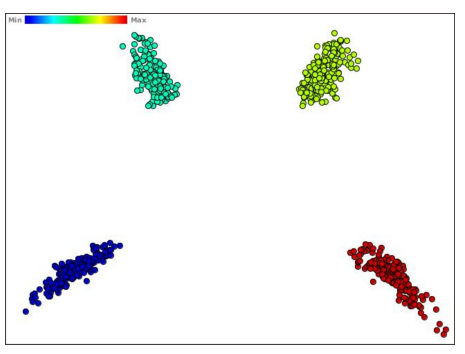

(a)

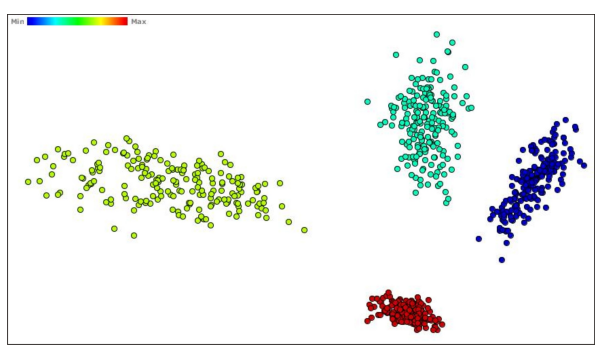

(b)

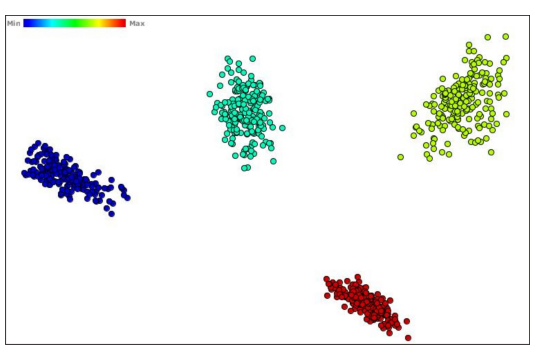

(c)

Figura 5.6: Técnica de Projeção Classical Scaling. (a) Projeção do conjunto original de dados. (b) Subconjunto de características selecionado pelo seletor proposto por Santos. (c) Subconjunto de características selecionado pelo seletor proposto neste trabalho.

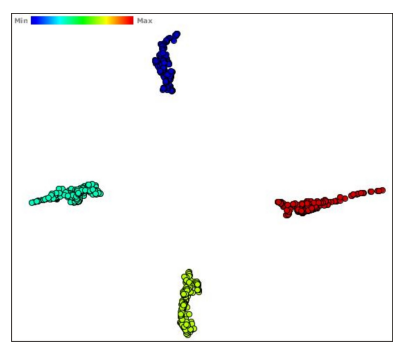

(a)

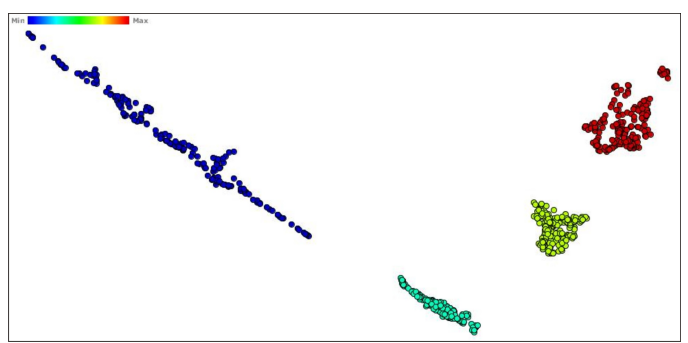

(b)

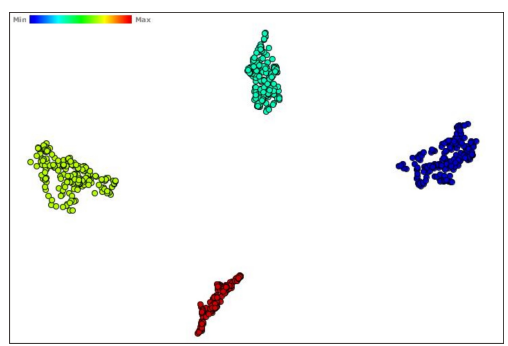

(c)

Figura 5.7: Técnica de Projeção Least Square Projection. (a) Projeção do conjunto original de dados. (b) Subconjunto de características selecionado pelo seletor proposto por Santos. (c) Subconjunto de características selecionado pelo seletor proposto neste trabalho.

\subsection{Experimento 3}

O terceiro experimento tem como objetivo principal avaliar o número correto de agrupamentos antes de particionar o conjunto de características que será usado pelo seletor por saliência proposto. Para isso, dois processos foram utilizados. O primeiro consiste do uso de um estima- 
dor do número ideal de agrupamentos, implementado por Hruschka [Hruschka and Covões 2005], que emprega o conceito de silhueta. O segundo processo consiste em aplicar o algoritmo $K G A$ clustering, para um número variado de agrupamentos $(k=3,4,5$ e 6$)$. Assim, podemos tanto avaliar o desempenho do estimador de Hruschka como também avaliar o comportamento do seletor por saliência proposto para variados valores de $k$.

Este experimento utilizou 200 imagens, pertencentes ao Banco Scene, de duas classes: construções e costas oceânicas. As características foram extraídas por meio dos Filtros de Gabor, para 4 escalas, 12 orientações e 3 medidas (média, variância e energia), resultando em 144 características. Além destas, foram extraídas as 6 características de Tamura. No total, cada imagem foi representada por um vetor com 150 características.

Para a realização do treinamento da rede neural, dividimos o conjunto de imagens em treino (150 imagens, sendo 75 por classe) e teste (50 imagens, sendo 25 por classe) e usamos o método Stratified $K$-fold-cross-validation, para $K=4$, para validar os resultados. Além disso, cada partição foi usada para realizar dois treinamentos da rede e a média foi obtida.

Inicialmente, o algoritmo de Hruschka foi aplicado no conjunto transposto $M_{m \times n}$, obtendo 3 como o número correto de agrupamentos. Portanto, as 150 características forma separadas em 3 grupos. A seguir, executou-se o algoritmo $K G A$-clustering para $k=3,4,5$ e 6 , consequentemente, quatro diferentes topologias da rede neural do seletor por saliência proposto foram consideradas (número de neurônios da camada oculta igual a 3,4,5 e 6). Apenas 30 características foram selecionadas em todos os casos, ou seja, 20\% do total. Para efeito de comparação o seletor por saliência desenvolvido por Santos [Santos and Batista Neto 2007] também foi utilizado. A Tabela 5.6 apresenta os resultados obtidos, considerando os diferentes números de agrupamentos.

Tabela 5.6: Média da taxa de erro de classificação considerando os subconjuntos selecionados pelos seletores por saliência, tratando a questão do número correto de agrupamentos.

\begin{tabular}{c|c|c|c|c|c}
\hline Método de Seleção & \multicolumn{5}{|c}{ Taxa de Erro de Classificação } \\
\hline & $k=3($ Hruschka $)$ & $k=3($ KGA & $k=4(K G A)$ & $k=5(K G A)$ & $k=6(K G A)$ \\
\hline Seletor Santos (30) & $1,75 \%$ & $1,75 \%$ & $11,4 \%$ & $8,5 \%$ & $1,75 \%$ \\
Seletor Proposto (30) & $2,75 \%$ & $2,75 \%$ & $2 \%$ & $2,25 \%$ & $2,75 \%$ \\
\hline
\end{tabular}

Ao observar a Tabela 5.6 percebe-se que as taxas de erro obtidas pelos subconjuntos de características resultantes do seletor por saliência proposto sofre pequenas variações quando se altera a quantidade de agrupamentos de características e, consequentemente, a quantidade de neurônios da camada oculta. Já o seletor proposto por Santos apresenta uma variação maior nos valores obtidos, quando se altera a quantidade de neurônios da camada oculta, chegando a 
obter uma taxa de erro de classificação de $11.4 \%$ quando se utiliza quatro neurônios na camada oculta, demonstrando sua instabilidade.

Após as seleções, os subconjuntos de características obtidos pelos dois seletores foram utilizados no cálculo de novas projeções para o conjunto total de imagens. Tais projeções foram geradas utilizando as técnicas $S M, C S$ e $L S P$. As Tabelas 5.7, 5.8 e 5.9 apresentam a média dos valores de silhueta obtidos, para cada uma das técnicas citadas.

Observando as Tabelas 5.7, 5.8 e 5.9 percebe-se pequenas variações nos valores de silhueta obtidos quando se utiliza os subconjuntos selecionados por ambos os seletores por saliência. Em muitos casos, o valor de silhueta da projeção aumenta após a seleção. No entanto, notase uma diminuição significativa do valor de silhueta obtido quando se utiliza o subconjunto selecionado pelo seletor por saliência proposto, onde o agrupamento das características foi feito pelo algoritmo de Hruschka. Diante disso, percebe-se a importância de se utilizar um bom mecanismo de agrupamento para particionar as características antes enviá-las para o seletor e ainda observa-se a superioridade do algoritmo KGA-clustering para particionar características, independente do número de grupos. Ressalta-se que as projeções não foram apresentadas devido à semelhança com as projeções do próximo experimento.

Tabela 5.7: Média das silhuetas obtidas para o conjunto de 200 imagens do banco Scene utilizando a técnica Sammon's Mapping.

\begin{tabular}{c|c|c|c|c|c}
\hline Método de Seleção & \multicolumn{5}{|c}{ Silhueta } \\
\hline & $k=3($ Hruschka) & $k=3(K G A)$ & $k=4(K G A)$ & $k=5(K G A)$ & $k=6(K G A)$ \\
\hline Seletor Santos (30) & 0,59 & 0,59 & 0,58 & 0,6 & 0,59 \\
Seletor Proposto (30) & 0,45 & 0,57 & 0,58 & 0,6 & 0,59 \\
\hline Sem Seleção (150) & \multicolumn{4}{|c}{0,54} \\
\hline
\end{tabular}

Tabela 5.8: Média das silhuetas obtidas para o conjunto de 200 imagens do banco Scene utilizando a técnica Classical Scaling.

\begin{tabular}{c|c|c|c|c|c}
\hline Método de Seleção & \multicolumn{5}{|c}{ Silhueta } \\
\hline & $k=3($ Hruschka $)$ & $k=3(K G A)$ & $k=4(K G A)$ & $k=5(K G A)$ & $k=6(K G A)$ \\
\hline Seletor Santos (30) & 0,67 & 0,67 & 0,66 & 0,67 & 0,67 \\
Seletor Proposto (30) & 0,49 & 0,64 & 0,66 & 0,66 & 0,67 \\
\hline Sem Seleção (150) & \multicolumn{5}{|c}{0,64} \\
\hline
\end{tabular}


Tabela 5.9: Média das silhuetas obtidas para o conjunto de 200 imagens do banco Scene utilizando a técnica Least Square Projection.

\begin{tabular}{c|c|c|c|c|c}
\hline Método de Seleção & \multicolumn{5}{|c}{ Silhueta } \\
\hline & $k=3($ Hruschka $)$ & $k=3(K G A)$ & $k=4(K G A)$ & $k=5(K G A)$ & $k=6(K G A)$ \\
\hline Seletor Santos (30) & 0,76 & 0,76 & 0,74 & 0,76 & 0,76 \\
Seletor Proposto (30) & 0,56 & 0,72 & 0,74 & 0,74 & 0,76 \\
\hline Sem Seleção (150) & \multicolumn{5}{|c}{0,74} \\
\hline
\end{tabular}

\subsection{Experimento 4}

O quarto experimento aborda apenas a seleção por meio da projeção de características com o objetivo de analisar a influência das técnicas de projeção Sammon's Mapping, Classical Scaling e Least Square Projection nos resultados obtidos. Além disso, comparam-se os resultados com a seleção de características puramente aleatória, com o intuito de mostrar que a seleção manual de características não consiste em um processo aleatório e sim, baseado nos agrupamentos de características obtidos, os quais possuem amostras com poder discriminatório semelhante. Este experimento utiliza as mesmas imagens e parâmetros do experimento anterior.

A primeira técnica de projeção utilizada foi a Least Square Projection. A Figura 5.8 ilustra uma projeção das 200 imagens para todas as características. Em seguida, foi realizado o processo de seleção proposto: o conjunto de dados foi transposto e projetado, revelando alguns agrupamentos, conforme ilustra a Figura 5.9(a). O usuário, então, selecionou algumas amostras de cada agrupamento, descartando as restantes, compondo um subconjunto com 30 características. Por fim, a Figura 5.9(b) ilustra a projeção das 200 imagens para o subconjunto gerado pela seleção visual.

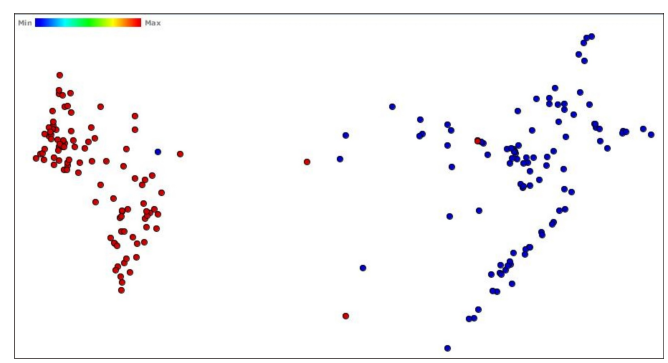

Figura 5.8: Projeção das 200 imagens para todas as características utilizando a técnica Least Square Projection.

Utilizando a técnica Classical Scaling, primeiramente projetamos as 200 imagens para o conjunto original de características, conforme apresentado na Figura 5.10. Em seguida, este 


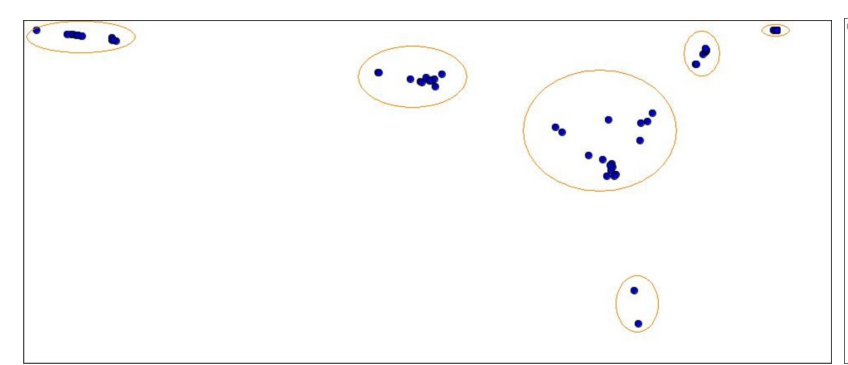

(a)

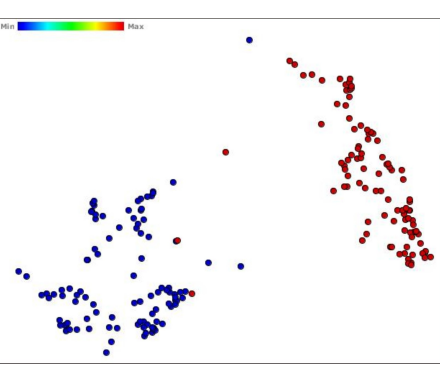

(b)

Figura 5.9: Técnica de Projeção Least Square Projection. (a) Projeção dos dados transpostos. Cada ponto representa uma característica. (b) Projeção das imagens para o subconjunto de 30 características.

conjunto foi transposto e projetado, revelando alguns agrupamentos, conforme pode ser observado na Figura 5.11(a), permitindo que o usuário selecionasse 30 amostras. A projeção das 200 imagens considerando apenas o subconjunto selecionado é apresentada na Figura 5.11(b).

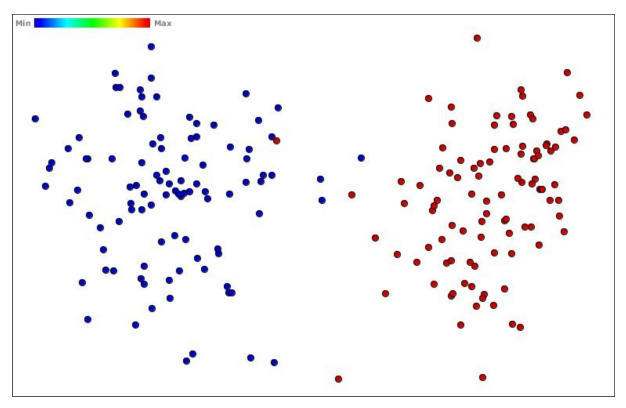

Figura 5.10: Projeção das 200 imagens para todas as características utilizando a técnica Classical Scaling.

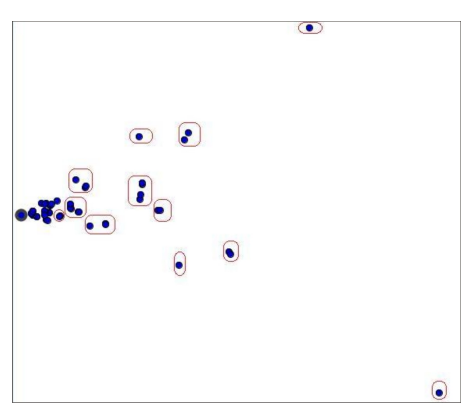

(a)

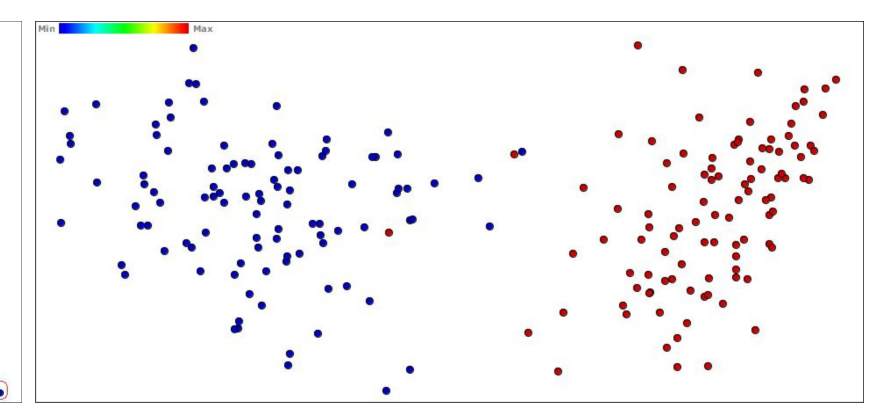

(b)

Figura 5.11: Técnica de Projeção Classical Scaling. (a) Projeção dos dados transpostos. Cada ponto representa uma característica. (b) Projeção das imagens para o subconjunto de 30 características.

Por fim, as projeções foram geradas utilizando a técnica Sammon's Mapping. A projeção 
das 200 imagens considerando todas as características é apresentada na Figura 5.12. Em seguida, este conjunto foi transposto e projetado, conforme pode ser visto na Figura 5.13(a). Esta projeção revelou alguns agrupamentos de características, dos quais o usuário selecionou 30 amostras. A Figura 5.13(b) ilustra a projeção das 200 imagens considerando apenas o subconjunto de características selecionado.

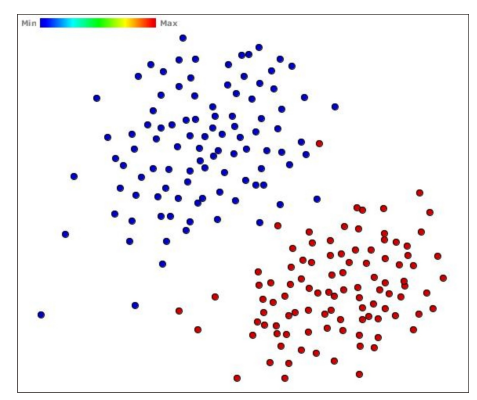

Figura 5.12: Projeção das 200 imagens para todas as características utilizando a técnica Sammon's Mapping.

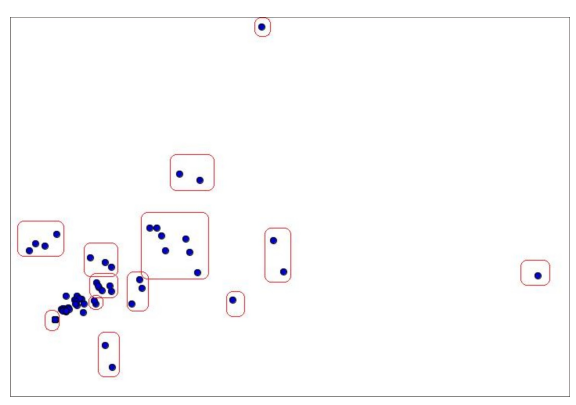

(a)

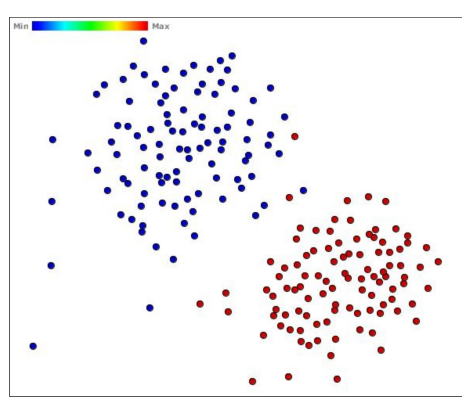

(b)

Figura 5.13: Técnica de Projeção Sammon's Mapping. (a) Projeção dos dados transpostos. Cada ponto representa uma característica. (b) Projeção das imagens para o subconjunto de 30 características.

Observando visualmente as projeções é possível verificar variações de acordo com a técnica utilizada. Estas variações são confirmadas pelas medidas de silhueta obtidas, conforme pode ser visto na Tabela 5.10, onde os valores entre parênteses indicam a quantidade de características empregada em cada projeção. Percebe-se que a técnica Least Square Projection projeta as duas classes de imagens com maior grau de separação e mantém os elementos de mesma classe mais coesos, o que é comprovado pelo maior valor de silhueta obtido (0.74) em relação às outras técnicas utilizadas. No entanto, quando as técnicas Classical Scaling e Sammon's Mapping são usadas, os subconjuntos de características selecionados, a partir dos agrupamentos obtidos na projeção, conseguem gerar novas projeções com valor de silhueta maior que àquele obtido 
quando se utiliza o conjunto completo de características. Além disso, pode-se perceber que o valor de silhueta obtido pelo subconjunto selecionado via Classical Scaling é equivalente àquele obtido pelo subconjunto selecionado via Least Square Projection. Isto pode ser explicado pelo fato da técnica Classical Scaling preservar melhor a distância dos dados originais nos dados projetados. Assim, a projeção resulta em agrupamentos de características com poder discriminatório semelhante, permitindo a seleção de um subconjunto mais representativo.

Tabela 5.10: Medidas de silhueta obtidas das projeções para o conjunto de 200 imagens de cenas naturais, considerando diferentes técnicas.

\begin{tabular}{c|c|c}
\hline Técnica de Projeção & Conjunto Original (150) & Conjunto Selecionado (30) \\
\hline \hline Least Square Projection & 0,74 & 0,68 \\
Classical Scaling & 0,64 & 0,68 \\
Sammon's Mapping & 0,54 & 0,58 \\
\hline
\end{tabular}

Para permitir uma análise adequada da influência das diferentes técnicas de projeção, cada subconjunto de característica selecionado visualmente foi utilizado na geração de novas projeções de imagens usando as três técnicas. Os resultados são apresentados na Tabela 5.11. Percebe-se que o melhor resultado (0.76) é dado pela projeção das imagens por meio da técnica Least Square Projection, onde o subconjunto de características foi selecionado usando a técnica Classical Scaling. Este resultado já era esperado, pois a técnica $C S$ é a que melhor preserva a distância dos dados originais nos dados projetados, permitindo a seleção de características mais representativas.

Tabela 5.11: Medidas de silhueta para o conjunto de 200 imagens do banco Scene, considerando os subconjuntos selecionados visualmente.

\begin{tabular}{c|c|c|c}
\hline & \multicolumn{3}{|c}{ Técnica de Projeção } \\
\hline Seleção - características projetadas com & $L S P$ & $C S$ & $S M$ \\
\hline$L S P$ & 0,68 & 0,58 & 0,51 \\
$C S$ & 0,76 & 0,68 & 0,59 \\
$S M$ & 0,73 & 0,67 & 0,58 \\
\hline
\end{tabular}

Complementando o experimento, três seleções de características foram realizados aleatoriamente. Em seguida, os subconjuntos foram usados para gerar novas projeções para o conjunto de imagens, utilizando as técnicas $L S P, C S$ e $S M$. As medidas de silhueta obtidas nas projeções são apresentadas na Tabela 5.12. Acrescentam-se as medidas de silhueta das projeções considerando o conjunto completo de características e os subconjuntos selecionados visualmente. 
Isto foi feito apenas para ressaltar a diminuição do valor da silhueta quando se utilizam características selecionadas aleatoriamente, ao contrário da seleção visual que mantém valores satisfatórios.

Tabela 5.12: Medidas de silhueta para o conjunto de 200 imagens do banco Scene, considerando os subconjuntos selecionados aleatoriamente.

\begin{tabular}{c|c|c|c}
\hline & $L S P$ & $C S$ & $S M$ \\
\hline Seleção Aleatória & 0,36 & 0,32 & 0,26 \\
Seleção Visual & 0,68 & 0,68 & 0,58 \\
Sem Seleção & 0,74 & 0,64 & 0,54 \\
\hline
\end{tabular}

\subsection{Considerações Finais}

Este capítulo apresentou os experimentos realizados para avaliar os diferentes aspectos da metodologia proposta. Os experimentos mostraram que a seleção de características baseada em projeção produz subconjuntos representativos, capazes de gerar novas projeções com qualidade visual semelhante às projeções que utilizam o conjunto original de dados, ressaltando que o redução do número de características é sempre bastante significativa. Mostrou-se que este processo não se trata de um processo puramente aleatório, que as diferentes técnicas de projeção influenciam nos resultados e que a maldição da dimensionalidade gerada quando se transpõe o conjunto de dados não chega a prejudicar a qualidade visual das projeções. Além disso, ao se comparar com a seleção de características por meio do algoritmo $K$-means, percebe-se que a seleção apoiada por projeção sempre obtém melhores resultados.

Em relação aos resultados obtidos pelo seletor por saliência proposto neste trabalho percebese que este é capaz de gerar subconjuntos de características representativos, responsáveis por baixas taxas de erro de classificação e por novas projeções com qualidade visual satisfatória, em alguns casos melhores que as projeções considerando todas as características. Pôde-se notar o quão importante é o agrupamento inicial das características, o qual será utilizado pelo seletor proposto para se calcular a saliência e definir a quantidade de neurônios da camada oculta. Ressalta-se que na maioria dos experimentos, o seletor proposto neste trabalho superou o seletor proposto por Santos [Santos and Batista Neto 2007], principalmente quando se trata da utilização dos subconjuntos de características selecionados para gerar projeções com melhor qualidade visual, além do fato da seleção dos subconjuntos ser realizada em um tempo menor, devido à diminuição da quantidade de cálculos para se obter as saliências. 


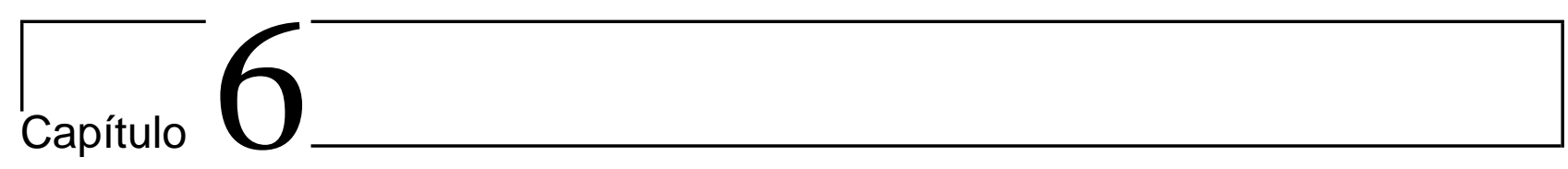

\section{Conclusões}

Este trabalho desenvolveu uma nova abordagem de seleção de características baseada em projeção de dados multidimensionais. Acredita-se que a combinação de seleção com técnicas de projeção seja vantajosa pois a avaliação da seleção, anteriormente baseada apenas em uma função estatística, conta agora com o ponto de vista de um observador (usuário) que avalia a qualidade do agrupamento fornecido pela projeção para um dado subconjunto de características. Além disso, pôde-se explorar a viabilidade de realizar a seleção de características de forma automática, combinando projeções com processos de agrupamento. Além da abordagem de seleção visual proposta, fez-se um aprimoramento no seletor por saliência baseado em rede neural MLP, desenvolvido por Santos [Santos and Batista Neto 2007]. Tal aprimoramento fez com que o cálculo da saliência seja feito considerando grupos de características e não mais o conjunto completo, o que diminui a quantidade de computações e provê um seletor mais rápido, robusto e eficiente.

Quando se trata da seleção de características por meio da projeção obtivemos resultados satisfatórios, ou seja, novas projeções com valores de silhueta semelhantes ou melhores que àqueles obtidos das projeções que usam o conjunto total de características. Além disso, pôde-se verificar a variação dos resultados de acordo com a técnica de projeção utilizada e comprovar que a seleção manual não se trata de um processo aleatório. Devido à falta de um protocolo padrão para comparar os resultados alcançados por esta abordagem, consideramos a seleção de características por meio de algoritmos de agrupamento, o que demonstrou a qualidade de nossa abordagem por meio dos valores de silhueta obtidos das projeções que utilizam os subconjuntos selecionados.

Em relação a seleção de características por meio do seletor por saliência proposto, nota-se a obtenção de subconjuntos de características capazes de gerar novas projeções com valores de silhueta satisfatórios e taxas de classificação de imagens elevadas. Além disso, ressalta- 
se a diminuição da quantidade de cálculos para a obtenção da saliência, visto que a quantidade de neurônios da camada oculta cai drasticamente, tornando o seletor proposto mais rápido. Ao se comparar com os resultados obtidos pelo seletor por saliência proposto por Santos [Santos and Batista Neto 2007] percebe-se que, na maioria das vezes, nosso seletor obtém taxas de classificação constantes, independente da variação do número de neurônios da camada oculta, e gera subconjuntos capazes de prover novas projeções com valores de silhueta melhores. Ressalta-se que o seletor de Santos foi comparado com outros seletores, obtendo melhores resultados [Santos and Batista Neto 2007]. Diante disse, demonstramos implicitamente a superioridade de nosso seletor em relação àqueles que foram superados pelo seletor de Santos.

\subsection{Limitações}

Quando se trata da seleção de características por meio da projeção deve-se ressaltar a possibilidade da transposição do conjunto de dados levar à maldição da dimensionalidade. Experimentos mostraram que a maldição da dimensionalidade não causa grandes prejuízos na projeção, ou seja, os subconjuntos selecionados geram novas projeções com qualidade visual satisfatória, mas, alguns cuidados podem ser tomados antes de transpor o conjunto de dados como, por exemplo, pode-se selecionar uma quantidade de instâncias (imagens) para representar o conjunto original de dados que não cause a maldição da dimensionalidade ao se transpor o conjunto, permitindo assim a seleção das características.

Uma outra questão a ser considerada é a técnica de projeção utilizada, pois esta influencia nos resultados, sendo necessária a utilização daquela que melhor preserve a relação de distância dos dados originais nos dados projetados. Já em relação ao seletor por saliência proposto, para o obtenção de resultados satisfatórios, as características devem ser particionadas por meio de um bom algoritmo de agrupamento, pois os grupos iniciais são responsáveis pela topologia da rede neural em que se baseia o seletor, influenciando no cálculo da saliência e, consequentemente, nos resultados obtidos.

Sabe-se que os conjuntos de imagens utilizados possuem uma quantidade relativamente pequena de imagens, sendo necessária a realização de alguns testes com grandes conjuntos de dados, lembrando sempre que na seleção baseada em projeção deve-se levar em consideração a maldição da dimensionalidade gerada pela transposição do conjunto. Além disso, é necessário realizar uma melhor avaliação da seleção manual de características, considerando um número maior de observadores (usuários). Dessa forma, é possível chegar a uma média que permita a validação dos resultados obtidos. 


\subsection{Contribuições}

As principais contribuições deste trabalho são:

- Desenvolvimento de uma nova abordagem de seleção de características baseada em projeção de dados multidimensionais, a qual permite que o usuário auxilie na seleção (seleção manual) e/ou torna viável a seleção automática de características por meio da combinação de projeções com técnicas de agrupamentos (aplicação do algoritmo K-means sobre os conjuntos transpostos e projetados).

- Aprimoramento do seletor de características baseado no cálculo da saliência de uma rede neural MLP, originalmente proposto por Santos [Santos and Batista Neto 2007]. Tal alteração diminui a quantidade de cálculos para a obtenção da saliência devido à modificação na configuração da rede neural artificial em que se baseia o seletor, tornando-o mais rápido e eficiente.

\subsection{Trabalhos Futuros}

Em trabalhos futuros pretende-se investigar o contraste obtido entre as taxas de classificação e os valores de silhueta das projeções. Após a seleção de um subconjunto de características, esperava-se que a taxa de classificação e, consequentemente, o valor de silhueta das projeções aumentassem. No entanto, os diversos experimentos realizados não permitiram que se estabelecesse uma relação entre estas duas medidas, pois nem sempre ocorreu o que se esperava. Acredita-se que tal resultado seja causado por alguma configuração da rede neural em que se baseia o seletor, sendo necessários mais alguns testes.

Em relação a projeção de características é preciso validar matematicamente a premissa de que a projeção de características gere grupos com características correlacionadas, passíveis de serem descartadas. Experimentalmente, obtivemos resultados bastante satisfatórios com os subconjuntos selecionados visualmente e pudemos observar a influência das diferentes técnicas de projeção nos resultados, no entanto, deve-se explicar matematicamente as razões para tais resultados. Para melhorar ainda mais o seletor por saliência proposto, pode-se testar diferentes algoritmos para estimar o número correto de agrupamentos, devido à influência desta informação na topologia da rede neural em que se baseia o seletor. Além disso, o agrupamento adequado das características é muito importante para a obtenção de resultados satisfatórios.

Ressalta-se a necessidade da realização de testes com grandes bancos de imagens. Além disso, pode-se usar diferentes extratores de características, o que permitirá a geração de vetores 
de alta dimensionalidade e com características correlacionadas, o que fará com que os processos de seleção de características obtenham resultados ainda mais satisfatórios. Por fim, destaca-se a necessidade de utilizar um número maior de usuários para realizar a seleção manual de características (seleção baseada em projeção). Este procedimento levará à obtenção de resultados mais confiáveis. 


\section{Referências Bibliográficas}

[Aggarwal 2005] Aggarwal, C. C. (2005). Towards exploratory test instance specific algorithms for high dimensional classification. In Proceedings of the 2005 ACM SIGKDD International Conference on Knowledge Discovery and Data Mining (KDD'05), pages 526-531.

[Aggarwal and Yu 2002] Aggarwal, C. C. and Yu, P. S. (2002). Redefining clustering for high-dimensional applications. IEEE Transactions on Knowledge and Data Engineering, $14(2): 210-225$.

[Anderberg 1973] Anderberg, M. R. (1973). Cluster Analysis for Application. Academic Press, New York.

[Bandyopadhyay and Maulik 2002] Bandyopadhyay, S. and Maulik, U. (2002). An evolutionary technique based on K-Means algorithm for optimal clustering in $\mathbb{R}^{N}$. Information Sciences, $146: 221-237$.

[Battiti 1994] Battiti, R. (1994). Using mutual information for selecting features in supervised neural net learning. IEEE Transactions Neural Network, 5(4):537-550.

[Bellman 1957] Bellman, R. E. (1957). Dynamic Programming. Princeton University Press, Princeton, NJ.

[Bhattacharyya 1943] Bhattacharyya, A. (1943). On a measure of divergence between two statistical populations defined by their probability distributions. Bulletin of the Calcutta Mathematical Society, pages 99-109.

[Blum and Langley 1997] Blum, A. and Langley, P. (1997). Selection of relevant features and examples in machine learning. Artificial Intelligence, 97:245-271. 
[Brandoli et al. 2010] Brandoli, B., Eler, M. D., Paulovich, F. V., Minghim, R., and Batista Neto, J. E. S. (2010). Visual data exploration to feature space definition. XXIII Brazilian Conference on Graphics, Patterns and Images, 1:32-39.

[Campos 2001] Campos, T. E. (2001). Técnicas de Seleção de Características com Aplicações em Reconhecimento de Faces. Master's thesis, Instituto de Matemática e Estatística, Universidade de São Paulo, São Carlos - SP.

[Castellano and Fanelli 2000] Castellano, G. and Fanelli, A. M. (2000). Variable selection using neural-network models. Neurocomputing, 31:1-13.

[Cox and Cox 2000] Cox, T. F. and Cox, M. A. A. (2000). Multidimensional Scaling. Chapman e Hall/CRC, second edition.

[Cuadros et al. 2007] Cuadros, A. M., Paulovich, F. V., Minghim, R., and Telles, G. P. (2007). Point Placement by Phylogenetic Trees and its Application to Visual Analysis of Document Collections. In Proceedings of IEEE Symposium on Visual Analytics Science and Technology - IEEE VAST, pages 99-106. IEEE CS Press.

[Eler et al. 2008] Eler, D. M., Nakazaki, M., Santos, D. P., Oliveira, M. C. F., Batista Neto, J., and Minghim, R. (2008). Multidimensional visualization to support analysis of image collections. In SIBGRAPI '08: Proceedings of the XX Brazilian Symposium on Computer Graphics and Image Processing (SIBGRAPI 2008), pages 289-296, Washington, DC, USA. IEEE Computer Society.

[Fisher 1938] Fisher, R. (1938). The statistical utilization of multiple measurements. In Annals of Egenics, 8:376-386.

[Fodor 2002] Fodor, I. K. (2002). A Survey of Dimension Reduction Techniques. Center for Applied Scientifc Computing, Lawrence Livermore National Laboratory. Relatório Técnico.

[Gabor 1946] Gabor, D. (1946). Theory of communication. Journal of Institute of Electronic Engineering, 93:429-457.

[Garson 1991] Garson, G. D. (1991). Interpreting neural net connection weights. AI Experts, $6(4): 46-51$.

[Haykin 1999] Haykin, S. (1999). Neural Networks: A comprehensive foundation. Prentice Hall, second edition. 
[Hruschka and Covões 2005] Hruschka, E. R. and Covões, T. F. (2005). Feature Selection for Cluster Analysis: an Approach Based on the Simplified Silhuette Criterion. Proceedings of the 2005 International Conference on Computational for Modelling, Control and Automation, and International Conference Intelligent Agents, Web Technologies and Internet Commerce (CIMCA-IAWTIC'05).

[Hruschka et al. 2004] Hruschka, E. R., de Castro, L. N., and Campello, R. J. G. B. (2004). Evolutionary Algorithms for Clustering Gene-Expression Data. Proc. of the 4 th IEEE International Conference on Data Mining 2004, pages 403-406.

[Huber and Dutra 1998] Huber, R. and Dutra, L. (1998). Feature Selection for ERS-1/2 InSAR classification: High dimensionality case. Geoscience and Remote Sensing Symposium Proceedings, 3:1605-1607.

[Jain et al. 2000] Jain, A., Duin, R. P. W., and Mao, J. (2000). Statistical Pattern Recognition: a Review. IEEE Transactions on Pattern Analysis and Machine Intelligence, 22(1).

[Jain and Zongker 1997] Jain, A. and Zongker, D. (1997). Feature Selection: Evaluation, Application and Small Sample Performance. IEEE Transactions on Pattern Analysis and Machine Intelligence, 19(2):153-158.

[Jain and Dubes 1988] Jain, A. K. and Dubes, R. C. (1988). Algorithms for Clustering Data. Prentice-Hall.

[Jolliffe 1986] Jolliffe, I. T. (1986). Principal Component Analysis. Springer-Verlag.

[Kaufman and Rousseeuw 1990] Kaufman, L. and Rousseeuw, P. J. (1990). Finding Groups in Data - An Introduction to Cluster Analysis. Wiley Series in Propability and Mathematical Statistics.

[Kirkpatrick et al. 1983] Kirkpatrick, S., Gelatt, C. D., and Vecchi, M. P. (1983). Optimization by Simulated Annealing. Science, New Series, 220(4598):671-680.

[Kohavi 1995] Kohavi, R. (1995). A study of Cross-Validation and Bootstrap for acurracy estimation and model selection. International Joint Conference on Artificial Intelligence $(I J C A I)$.

[Korn et al. 2001] Korn, F., Pagel, B., and Faloutsos, C. (2001). On the 'Dimensionality Curse' and the 'Self-Similarity Blessing'. IEEE Transactions on Knowledge and Data Engineering, 13(1). 
[Kudo and Sklansky 2000] Kudo, M. and Sklansky, J. (2000). Comparison of algorithms that select features for pattern classifiers. Pattern Recognition, 33(1):25-41.

[Leray and Gallinari 1999] Leray, P. and Gallinari, P. (1999). Feature Selection with Neural Networks. Behaviormetrika, 26(1):145-166.

[Liu and Yu 2005] Liu, H. and Yu, L. (2005). Toward integrating feature selection algorithms for classification and clustering. IEEE Transactions on Knowledge and Data Engineering, 17(4):491-502.

[Lloyd 1982] Lloyd, S. P. (1982). Least Square Quantization in PCM. IEEE Transactions on Information Theory, 28(2):129-137.

[MacCulloch and Pitts 1943] MacCulloch, W. and Pitts, W. (1943). A Logical Calculus of the Idea Immanent in Nervous Activity. Bulletin of Mathematical Biophysics, 5:115-133.

[Mahalanobis 1936] Mahalanobis, P. C. (1936). On the generalised distância in statistics. Proceedings of the National Institute of Sciences of India, 2(1):49-55.

[Mao and Jain 1995] Mao, J. and Jain, A. K. (1995). Artificial Neural Network for feature extraction and multivariate data projection. IEEE Transactions Neural Network, 6:296-317.

[Mao et al. 1994] Mao, J., Mohiuddin, K., and Jain, A. K. (1994). Parsimonious network design and feature selection through node pruning. In Proceedings of 12th International Association of Pattern Recognition (IAPR) Conference, 2:622-624.

[Nakariyakul and Casasent 2007] Nakariyakul, S. and Casasent, D. P. (2007). Adaptive Branch and Bound Algorithm for Selecting Optimal Features. Pattern Recognition Letters, 28(12):1415-1427.

[Narendra and Fukunaga 1977] Narendra, P. M. and Fukunaga, K. (1977). A Branch and Bound Algorithm for Feature Subset Selection. IEEE Transactions Computers, 26(9):917922.

[Nath et al. 1997] Nath, R., Rajagopalan, B., and Ryker, R. (1997). Determining the saliency of input variables in neural network classifiers. Computers e OR, 24(8):767-773.

[Paulovich 2008] Paulovich, F. V. (2008). Mapeamento de Dados multi-dimensionais - integrando mineração e visualização. $\mathrm{PhD}$ thesis, Universidade de São Paulo. 
[Paulovich et al. 2008] Paulovich, F. V., Nonato, L. G., Minghim, R., and Levkowitz, H. (2008). Least Square Projection: A Fast High-Precision Multidimensional Projection Technique and Its Application to Document Mapping. IEEE Transactions on Visualization and Computer Graphics, 14(3).

[Paulovich et al. 2007] Paulovich, F. V., Oliveira, M. C. F., and Minghim, R. (2007). The Projection Explorer: A Flexible Tool for Projection-based Multidimensional Visualization. In SIBGRAPI'0\%: Proceedings of the XX Brazilian Symposium on Computer Graphics and Image Processing, pages 27-34.

[Pudil et al. 1994] Pudil, F. J., Novovicová, J., and Kittler, J. (1994). Floating search methods in featur selection. Pattern Recognition Letters, pages 1119-1125.

[Rosenblatt 1958] Rosenblatt, F. (1958). The Perceptron: a propabilistic model for information storage and organization in the brain. Psychological Review, 65:386-408.

[Rumelhart and McClelland 1986] Rumelhart, D. and McClelland, J. (1986). Parallel distributed processing. Cambridge, MA: MIT Press, 1.

[Said 2005] Said, Y. H. (2005). Handbook of Statistics, volume 24, chapter On Genetic Algorithms and their Applications. Elsevier B.V.

[Sammon 1969] Sammon, J. W. (1969). A nonlinear mapping for data structure analysis. IEEE Transactions on Computer, 18(5):401-409.

[Santos and Batista Neto 2007] Santos, D. P. and Batista Neto, J. E. S. (2007). Feature Selection with Equalized Salience Measures and its Application to Segmentation. In SIBGRAPI '0\%: Proceedings of the Brazilian Symposium on Computer Graphics and Image Processing, pages 253-262.

[Selim and Ismail 1984] Selim, S. Z. and Ismail, M. A. (1984). K-means type algorithms: a generalized convergence theorem characterization of local optimality. IEEE Transactions Pattern Anal. Mach. Inteli 6, pages 81-87.

[Siedlecki and Sklansky 1989] Siedlecki, W. and Sklansky, J. (1989). A note on Genetic Algorithms for Large-Scale Feature Selection. Pattern Recognition Letters, 10(5):335-347.

[Somol et al. 2000] Somol, P., Pudil, P., Ferri, F., and Kitlter, J. (2000). Fast Branch and Bound Algorithm in Feature Selection. Proceedings of 6th World Multiconference on Systemics, Cybernetics and Informatics(SCI2000), pages 646-651. Orlando, Florida, USA. 
[Somol et al. 2001] Somol, P., Pudil, P., and Grim, J. (2001). Branch and Bound Algorithm with Partial Prediction for use with Recursive and non-Recursive Criterion Forms. Proceedings of Second Internationl Conference on Advances in Pattern Recognition (ICAPR2001), pages 230-239. Rio de Janeiro, Brasil.

[Sousa 2006] Sousa, E. P. M. (2006). Identificação de Correlações Usando a Teoria dos Fractais. $\mathrm{PhD}$ thesis, Instituto de Ciências Matemáticas e de Computação, Universidade de São Paulo, São Carlos - SP.

[Steyvers 2002] Steyvers, M. (2002). Multidimensional Scaling. In. Encyclopedia of Cognitive Science.

[Tamura et al. 1978] Tamura, H., Mori, S., and Yamawaki, T. (1978). Textural Features Corresponding to Visual Perception. IEEE Transactions on Systems, Man and Cybernetics, 8(6):460-473.

[Tan et al. 2006] Tan, P. N., Steinbach, M., and Kumar, V. (2006). Introduction to Data Mining. Addison-Wesley.

[Tejada et al. 2003] Tejada, E., Minghim, R., and Nonato, L. (2003). On Improved projection techniques to support visual exploration of multidimensional data sets. Information Visualization, 2(4):218-231.

[Torgerson 1952] Torgerson, W. (1952). Multidemnsional Scaling: Theory and method. Psychometrika, 17(4):401-419.

[Webb 2002] Webb, A. (2002). Statistical Pattern Recognition. John Wiley \& Sons, LTD, second edition.

[Wong 1999] Wong, P. (1999). Guest editor's introduction: Visual data mining. IEEE Compuer Graphics and Applications, 19:20-21.

[Young and Householder 1938] Young, G. and Householder, A. (1938). Discussion of a set of points in terms of their mutual distances. Psychometrika, 3(1):19-22. 